University of Massachusetts Amherst ScholarWorks@UMass Amherst

Doctoral Dissertations 1896 - February 2014

$1-1-1978$

\title{
Guilt, attribution of responsibility, and resolution of the divorce crisis.
}

Linda Ceriale Peterson

University of Massachusetts Amherst

Follow this and additional works at: https://scholarworks.umass.edu/dissertations_1

\section{Recommended Citation}

Peterson, Linda Ceriale, "Guilt, attribution of responsibility, and resolution of the divorce crisis." (1978). Doctoral Dissertations 1896 February 2014. 4610.

https://scholarworks.umass.edu/dissertations_1/4610

This Open Access Dissertation is brought to you for free and open access by ScholarWorks@UMass Amherst. It has been accepted for inclusion in Doctoral Dissertations 1896 - February 2014 by an authorized administrator of ScholarWorks@UMass Amherst. For more information, please contact scholarworks@library.umass.edu. 
FIVE COLLEGE DEPOSITORY 


\title{
GUILT, ATTRIBUTION OF RESPONSIBILITY, AND RESOLUTION OF THE DIVORCE CRISIS
}

\author{
A Dissertation Presented \\ By \\ LINDA CERIALE PETERSON
}

Submitted to the Graduate School of the University of Massachusetts in partial fulfillment of the requirements for the degree of

DOCTOR OF EDUCATION

May 1978

Education 
(C) Linda Ceriale Peterson 1978 All Rights Reserved 
GUILT, ATTRIBUTION OF RESPONSIBILITY, AND RESOLUTION OF THE DIVORCE CRISIS

A Dissertation Presented By

LINDA CERIALE PETERSON

Approved as to style and content by:

Dy. John W. Wideman Chairperson of Committee

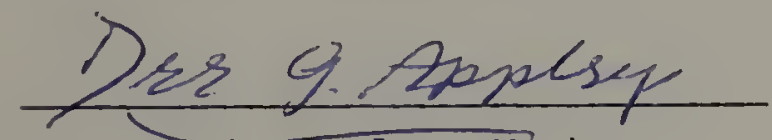

Dr. Dee G. App ley, Member

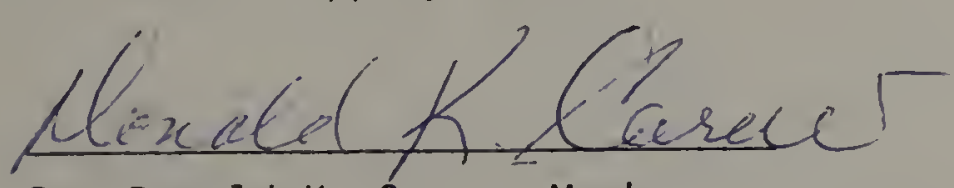

Dr. Donald K. Carew, Member

Gimintantiin

Mario Fantini, Dean School of Education

i i i 


\section{DEDICATION}

To my mother: whose strength and endurance have been an inspiration; whose generosity and warmth have been invaluable and not appreciated enough; whose outstanding values have enriched and influenced my own life; whose unceasing love has been and will continue to be an everlasting source of comfort;

I offer tribute in dedicating this dissertation. 


\section{ACKNOWLEDGMENTS}

Deep appreciation is extended to my committee: Dee Appley, Don Carew, and especially, Jack Wideman, for their guidance and knowledge during all phases of this dissertation; and to my dear friend, Judith Karshmer, for her help and attentive listening during some crucial periods.

Special gratitude is given to my family: my parents, Gabrielle, Bill, Phyllis, and Virginia. Their love and support during all phases of my life have greatly enriched my place-in-the-world.

My ultimate goal has been largely aided by my husband, Robert, whose love, caring, and patience have been a source of great comfort and fulfillment. 


\section{ABSTRACT}

\section{Guilt, Attribution of Responsibility, and Resolution of the Divorce Crisis \\ (May 1978) \\ Linda Ceriale Peterson \\ B.S., Fairleigh Dickinson University \\ M.A., New York University \\ Ed.D., University of Massachusetts \\ Directed by: Professor John W. Wideman}

Divorce is a major social problem, on the increase, and usually generating personal crises for those involved. Yet crises are occasions for personal growth if a person can resolve them constructively. This study was designed to answer three main questions regarding the resolution of the divorce crisis. Firstly, what is the relationship between guilt and the resolution of the divorce crisis? The literature suggests, according to the prevailing societal attitudes, that divorce is a wrongful act in failing to maintain the marriage. Hence, people who have a predisposition to over-reacting to societal attitudes and find themselves incapacitated by a chronic state of guilt, may have difficulty resolving the divorce crisis.

Secondly, what is the relationship between single attribution of responsibility (to self, to ex-spouse, or to external factors) and the resolution of the divorce crisis? The literature supports the notion that attributing responsibility, i.e., assigning cause, is an on- 
going process an individual does for the purpose of understanding behaviors or events during a crisis. It would seem useful, then, to ascertain whether or not attributing responsibility for the marriage terminating to one person or thing has any influence on how well the divorce crisis is resolved.

Thirdly, what is the relationship between multiple attributions of responsibility and the resolution of the divorce crisis? It has been purported in the literature that there are usually many causes or reasons for the occurrence of a unitary event. The divorcee, who considers various explanations or makes multiple attributions for the occurrence of the marriage terminating, has a greater sense of reality and uses more careful thought than one who makes a single attribution. Consequently, divorcees making multiple attributions might have less difficulty in resolving the divorce crisis than those making a single attribution.

Secondary questions involve the relationship between various characteristics (age, sex, number of years married, number of children, number of marriages, income, religiosity, employment, having an intimate relationship, and initiating the divorce proceedings) and guilt as well as the relationship between the same characteristics and divorce resolution.

The sample consisted of 170 men and women who had been granted a divorce from the Hampshire County Court of Massachusetts during December 1975 through September 1976. The entire data collection was done via the mail. The investigator sent an initial letter of explanation 
followed by the questionnaires and a personal data sheet requesting relevant information examining the variables being tested: guilt, attribution of responsibility, and resolution of the divorce crisis. The data was subjected to multiple regression analysis and an $F$ ratio was evaluated at the .05 level of significance for each hypothesis tested.

The findings were as follows: (1) guilt was not related to the resolution of the divorce crisis; (2) single attribution of responsibility to ex-spouse was significantly related to a negative resolution; (3) multiple attributions which excluded ex-spouse were significantly related to a positive resolution; (4) religiosity and initiating the divorce proceedings were significantly related to guilt; and (5) having an intimate relationship and initiating the divorce proceedings were significantly related to a positive resolution.

These findings suggest that the level of guilt is not as crucial in resolving the divorce crisis as the ability to respond and take action in one's own behalf. Making multiple attributions of responsibility which excluded ex-spouse, initiating the divorce proceedings, and having an intimate relationship suggest an affirmation of one's agency: an ability to respond and take action. Attributing responsibility to the ex-spouse, however, suggests a denial of one's agency and possibly a continuation of feeling helpless and/or bitter about the divorce experience. Furthermore, these findings have significance for all who are involved with divorce, particularly those in the helping professions and those in the legal system. 
ACKNOWLEDGMENTS

ABSTRACT ................................. $v i$

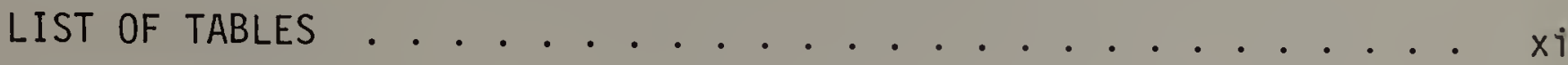

Chapter

I. THE PROBLEM ..................... 1

Introduction ................... 1

Statement of the Problem ............ 2

Sub Problems .................. 2 2

Definition of Terms . . . . . . . . . . . 2

Basic Assumptions . . . . . . . . . . . . . . 5

Hypotheses . . . . . . . . . . . . . . . 5

Need for the Study . . . . . . . . . . . . 7

Theoretical Framework . . . . . . . . . . . 11

I I. RELATED LiterATURE . . . . . . . . . . . . 19

Divorce as a Crisis............. . . . 19

Internal Forces on Resolution of Divorce Crisis . . . . . 26

External Forces on Resolution of Divorce Crisis . . . . . 32

III. METHODOLOGY . . . . . . . . . . . . . . . . . . . . 47

Sample ................ . . 47

Data Collection . . . . . . . . . . . . . 48

Measurement of Variables . . . . . . . . . . 50

IV. RESULTS OF THE STUDY . . . . . . . . . . . . . 54

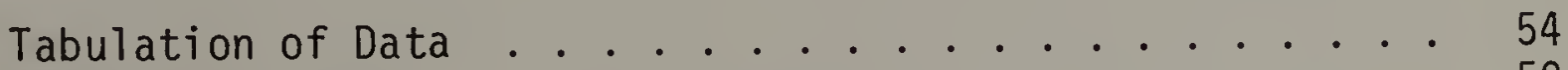

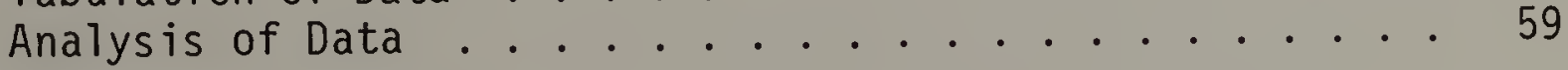

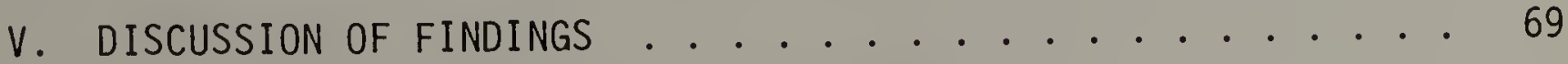

VI. SUMMARY, CONCLUSIONS, AND IMPLICATIONS . . . . . . . 81

Summary ................... . . . 81

Conclusions . . . . . . . . . . . . . . . . . . . 84

Implications .................. 85 
REFERENCES . . . . . . . . . . . . . . . . . . . . . . . . . . . . . 92

\section{Appendix}

A. MATERIALS FOR COLLECTION OF DATA . . . . . . . . . . . . . . 100

B. DATA . . . . . . . . . . . . . . . . . . . . . . 114 


\section{LIST OF TABLES}

Table

1. Characteristics of Sample Page

2. Tabulation of Scores on Guilt and Resol. . . . . . . 55

3. Summary of Multiple Regression Analys is for Dependent Variabi. 58 (Divorce Resolution) and Independent Variables (Guilt, Single Attributions of Responsibility, and Combinations of Guilt and Single Attributions)

4. Summary of Multiple Regression Analysis for Dependent Variable

(Divorce Resolution) and Independent Variables (Multiple Attributions)

5. Summary of Multiple Regression Analysis for Dependent Variable (Guilt) and Independent Variables (Characteristics) . .

6. Summary of Multiple Regression Analys is for Dependent Variable
(Divorce Resolution) and Independent Variables
(Characteristics) . . . . .

6. Summary of Multiple Regression Analys is for Depende
(Divorce Resolution) and Independent Variables
(Characteristics)

6. Summary of Multiple Regression Analysis for Depende
(Divorce Resolution) and Independent Variables
(Characteristics)

7. Raw Scores of Divorce Resolution, Guilt, Attribution of

Responsibility, Multiple Attributions, Single Attributions . 115

8. Frequency of Data on Characteristics of Sample ...... 125 


\section{CHAPTER I}

THE PROBLEM

\section{Introduction}

It is generally acknowledged that divorce, like any serious change in a person's life, is experienced as a crisis. Some individuals move through the crisis and find continued or even greater fulfillment in life. Many lose themselves in personal struggle, loneliness, and suffering. Others have more difficulty and are thrown into chronic and devastating self defeat.

For these reasons, the effort to study and understand the dynamic process of the psychological and social pressures generated by the experience of divorce should produce worthwhile information. Due to the complex nature of human interaction, there are probably a myriad of psychological and social factors which contribute to various outcomes of the divorce process.

This study, however, will only investigate two: the level of guilt of the divorced person and the attribution of responsibility made by the divorced person for the marriage terminating. These seem central in their relationship to the outcome of the divorce experience.

Information gleaned from such a study might prove useful in predicting, preventing, or treating destructive outcomes and in facilitating positive ones. 


\section{Statement of the Problem}

What effects do the interactions between guilt and the attribution of responsibility to self, to ex-spouse, to external factors have on the resolution of the divorce crisis?

\section{Sub Problems}

1. What is the relationship between guilt and the resolution of the divorce crisis?

2. What is the relationship between single attribution of responsibility (to self, to ex-spouse, or to external factors) and the resolution of the divorce crisis?

3. What is the relationship between multiple attributions of responsibility and the resolution of the divorce crisis?

4. What is the relationship between various characteristics (income, religiosity, having an intimate relationship, age, sex, number of children, number of years married, number of marriages, employment, and initiator of divorce proceedings) and guilt?

5. What is the relationship between various characteristics (income, religiosity, having an intimate relationship, age, sex, number of children, number of years married, number of marriages, employment, and initiator of divorce proceedings) and the resolution of the divorce crisis?

\section{Definition of Terms}

Guilt. One blames oneself for violating or failing to attain internal- 
ized standards of proper behavior and considers oneself a terrible person for having done terrible things (Mosher, 1965, p. 162). In this study guilt is considered a generalized chronic tendency or personality disposition (Mosher's term) as opposed to a temporary reaction to a given situation (Mosher, 1965, p. 162). This guilt can be projected on to another whereby one blames the other for violating or failing to attain internalized standards of proper behavior and considers the other a terrible person for having done a terrible thing (Horney, 1937, p. 246).

Crisis. A period of threat to the individual which severely challenges the continuation of the individual's present way of living and experiencing self. Tension rises within the individual and gives way to disorganization. This is followed by reorganization which eventually leads to resolution (Caplan, 1964, pp. 38-41).

Resolution. The outcome of a crisis whereby the individual, through the interaction of internal (psychological and physical) and external (environmental) forces, reorganizes with new coping behavior (Caplan, 1964, pp. 53-54).

Positive resolution. Tension decreases within the individual so that functioning is resumed to the same level or higher level than prior to the crisis. Activities of daily living are resumed in maintaining physiological needs (rest, nutrition, shelter, sexuality) and psychological needs (acceptance of self, assertion, expression of feelings, intimacy with others). These needs are met by the individual alone or 
with the help of interpersonal and/or community resources (Rapoport [Parad], 1972, pp. 26-29).

Negative resolution. Tension continues within the individual so that functioning is at a lower level than prior to the crisis. Since activities of daily living are not adequately resumed, some of the physiological and psychological needs are not met by the individual nor is the individual able to seek interpersonal and/or community resources in helping meet those needs.

Attribution of responsibility. The cognitive process by which the individual assigns cause for the purpose of understanding behaviors or events (Jones, Kanouse, Kelley, Nisbett, Valins \& Weiner, 1972, p. x). In this study it will mean assigning the cause or reason for the marriage terminating to oneself, to one's ex-spouse, to external factors, or to a combination of the above.

Single attribution. Attributing responsibility to oneself, or to exspouse, or to external factors.

Multiple attributions. Attributing responsibility to oneself and at least one other: ex-spouse or one of the external factors.

External factors. People or things outside the couple relationship; for example, children, families of origin, job, economic condition, luck, etc. 


\section{Basic Assumptions}

1. The individual is an open system constantly changing and affecting change in others through the interaction of input and output of energy or messages due to the inherent qualities of interrelationships between and interdependence of all systems (Watzlawick, Beavin, \& Jackson, 1967, p. 127; A11port [Buckley], 1968, p. 345).

2. Divorce is a crisis (Holmes \& Rahe, 1967, p. 218; Wiseman, 1975, p. 205; Goode, 1964, pp. 92-93).

3. Every crisis presents both an opportunity for psychological growth and the danger of psychological deterioration (Caplan, 1964, p. 53).

4. The outcome of a crisis depends on the interplay of internal and external forces in the course of the crisis (Caplan, 1964, p. 53).

\section{Hypotheses}

1. Guilt will be inversely related to the positive resolution of the divorce crisis.

The reason for the prediction that guilt will have a negative effect on the resolution of the divorce crisis is that the kind of guilt which will be measured in this study is experienced by the individual with an accompanying moral conviction that the wrongdoing "should not" have been committed or that the particular goal "ought to" have been attained. The individual is rigidly fixed with certain standards of proper behavior and that to have transgressed these standards by onese $\mathrm{f}$ 
or other means that whoever was responsible, not only did a terrible thing, but also is a terrible person: unworthy and incompetent. Consequently, the individual, with the guilt, is so immobilized that positive action cannot be taken in order to correct the wrongdoing, redefine certain goals better suited for his/her capacities, or re-evaluate the standards of behavior.

2. Positive resolution of the divorce crisis will not be significantly related to any of the single attributions of responsibility: (a) to self, (b) to ex-spouse, or (c) to external factors.

3. Positive resolution will be significantly related to multiple attributions as opposed to single attribution.

The reason multiple attributions will have greater significance is that there are usually many causes or reasons for the occurrence of a unitary result, especially when the result (termination of a marriage) has involved an interactional or open system (husband and wife). Therefore, more careful thought is needed in considering various explanations (multiple attributions to the occurrence of an event). In addition to more thought, a greater sense of reality is needed by the individual in order to view the result as having had more than one attribution. Consequently, the individual who uses more careful thought and has a greater sense of reality (i.e., making multiple attributions) is more apt to have an even greater positive resolution than does the person who does not, i.e., the person who makes a single attribution.

4. There is no significant relationship between various characteristics (income, religiosity, having an intimate relationship, age, sex, number of children, number of years married, number of marriages, 
employment, and initiator of divorce proceedings) and guilt.

5. There is no significant relationship between various characteristics (income, religiosity, having an intimate relationship, age, sex, number of children, number of years married, number of marriages, employment, and initiator of divorce proceedings) and resolution of the divorce crisis.

\section{Need for the Study}

Research in the area of divorce is limited in both quantity and quality. The only research of any substance has dealt with causes of divorce, background factors of the divorce-prone individual, and methods of preventing divorce. The aftermath of divorce has been investigated to an even lesser extent. Moreover, no one has studied the attribution of responsibility/guilt mechanism and its relationship to the resolution of divorce.

Justification of the study. It has been purported (Goode, 1964; Waller, 1967; Kessler, 1975; Fisher, 1974; Krantzler, 1973; Hunt, 1966; Weiss, 1975; Bohannon, 1970; Hallett, 1974) that divorce is a catastrophe inevitably creating serious adjustment problems which vary from individual to individual. Even though there has not been any investigation to determine how many and/or the extent to which individuals of the divorced population do encounter adjustment problems of a long range nature, Carter and Glick (1970) have given some indication of the seriousness of the problem through their examination of the vital statistics from the National Center for Heal th Statistics. 
In compiling age-adjusted death rates from specific causes for white persons 15-64 years old during 1959-1961, Carter and G1ick (1970, p. 347) found that the suicide rate for divorced women was 3.9 times greater than for married women and for divorced men it was 4.2 times greater than for married men. These death rates might be indicative of serious difficulties after the divorce of maladjusted tendencies prior to or during the course of the marriage.

Death rates from tuberculosis, pneumonia, and cirrhosis of the liver (linked with alcoholism) were 2.5 to 3 times greater for divorced women than for married women and 7 to 8.7 times greater for divorced men than married men. Carter and Glick (1970, p. 348) suggested that these rates possibly indicated an underlying neglect of personal health in the wake of the divorce crisis which is often characterized by poverty, bad housing, poor nutrition, and other circumstances which increase exposure to, and weaken resistance to, infection with disease.

Death rates from accidental deaths involving fires or explosions, falls, and motor vehicles were 2.5 to 3.3 times greater for divorced women than married women and 3.7 to 6.5 times greater for divorced men than married men. A possible explanation for these rates was proposed by Carter and Glick (1970, p. 349): preoccupation with adjustment problems; consequently, increased vulnerability to serious mishaps. An alternative reason might be the unconscious wish to die.

Another astonishing death rate was due to homicide: it was 4.9 times greater with divorced women than for married women and 6.7 times greater with divorced men than for married men. Carter and Glick (1970, p. 349) considered these might have reflected strong reactions to an im- 
pending remarriage or other conduct of the estranged spouse.

In addition to these inordinately high death rates among the divorced, studies on the association of psychiatric disorders and the divorced in psychiatric inpatients (Blacker, 1958; Taube, 1970; Malzberg, 1964) and psychiatric outpatients (Taube, 1970; Woodruff, Guze \& Clayton, 1972) revealed the rate of divorce among psychiatric patients was greater than in the general population. Smith (1971) found divorce/ separation to be one of the five life events having occurred significantly more frequently in lives of psychiatric inpatients as compared to a control sample from the general population. He also discovered that divorce/separation tended to precede the onset of mental disorders frequently enough for it to be considered a significant risk marker. Finally, Briscoe, Smith, Robins, Marten, and Gaskin (1973) reported that the divorced are significantly more likely to have psychiatric disorders than were married persons.

Children of the divorced can have equally disruptive and devastating Tives (Bernstein \& Robey, 1962; Landis, 1960; McDermott, 1968). Wylie and Degado (1959), Short [Hoffman \& Hoffman] (1966), and Glueck and Glueck (1952) found that delinquent children much more frequently came from separated/divorced families. Other studies (Burn, 1964; Buchinal, 1964; Otterstrom, 1952) indicated that children from divorced families generally demonstrated greater signs of maladjustment than children from intact homes. Lastiy, Westman, Cline, Swift, and Kramer (1970) reported a significant number of divorces in their study, one third, were followed by turbulence that could be pathogenic for affected children. They pointed out, however, that the experience of divorce it- 
self was less pathogenic than the nature of the patients' personalities and the relationships with their children. Consequently, this suggests that if parents have not positively resolved the divorce experience, then their unresolved conflicts may jeopardize the continued rearing of their children.

Caution is needed to prevent extrapolating definite causal correlation between divorce and the findings of the preceding studies. In fact, some of these difficulties might have existed prior to the divorce. Nevertheless, there is strong evidence that suggests difficulties and problems can arise and persist for the divorced, so much so, there can be interference not only with the individual's coping but also with the effective rearing of children.

Therefore, it would be important to know what causes these problems and/or what can be helpful once these problems emerge. Hopefully, this study will generate some possibilities. More specifically, it will determine what effect attribution of responsibility and guilt have on the resolution of the divorce crisis.

Incidence of divorce. The following reported numbers of divorce in the United States attests to the rising levels: 523,000 in $1967 ; 639,000$ in $1969 ; 715,000$ in 1970--provisional; and 839,000 in 1972--provisional (National Center for Health Statistics, 1973, pp. 1-2). Considering these trends, it is estimated that over $40 \%$ of the new marriages will end in divorce (Kessler, 1975, p. 1). In addition, Hetherington, Cox, and $\operatorname{Cox}(1976)$ state that the number of divorces involving children is rising to about $66 \%$ even though the birth rate is declining. Moreover, 
the rising rate of remarriages has not kept pace with the divorce rate, especially in families where children are involved. Therefore, during the past decade, there has been an increase in the proportion of divorced persons, particularly divorced parents, relative to partners in intact marriages ( $p .1)$.

Significance of study. This study will supply data for the further understanding of the dynamic processes involved during a critical phase in the individual's life cycle: divorce. It will add to the body of knowledge about predicting, preventing, and treating negative resolutions of the divorce crisis.

Since divorce is a social phenomenon affecting practically all members of society, this kind of knowledge might have significance for anyone related to marriage. Besides those individuals who are actually experiencing divorce, results from this study might be useful for legislators in their making laws about divorce and for lawyers in their giving legal service during the divorcing procedure. In addition, these results might be of particular interest to those in the helping professions for their planning and implementing intervention during this specific life crisis of divorce.

\section{Theoretical Framework}

This study will test the premise that attribution of responsibility and guilt are linked with the resolution of the divorce crisis by examining the level of resolution in individuals experiencing a divorce who vary in attributing responsibility to oneself, one's ex- 
spouse, and/or external factors and who vary in degrees of chronic guilt. Therefore, attribution of responsibility, guilt, and resolution of the divorce crisis are the three constructs which form the theoretical basis for this study.

Attribution of responsibility is the cognitive process by which the individual assigns cause for the purpose of understanding behaviors or events (Jones et al., 1972, p. x). This notion is part of attribution theory, an amorphous collection of observations about naive causal inference in the field of social psychology. Attribution theory is largely based on the work done by Fritz Heider (1958) who coined the phrase "naive psychology" since it is concerned with the cause-effect analyses of behavior made by the "man in the street."

Although attribution theory, as yet, does not claim a set of interrelated deductive principles (Jones et al., 1972, p. x), there are certain characteristics of the attribution process which have relevance in understanding some behaviors. The following general ones underlie many of the others: the individual attempts to assign a cause for important instances of his/her behavior and that of others; the assignment of cause is determined in a systematic manner; and the particular cause attributed for a given event has important consequences for subsequent feelings and behavior (Jones et al., 1972, p. xi).

Furthermore, it has been suggested (Kelley [Jones et al.], 1972 , p. 22) that the attribution process is motivated by the individual's need to give stable meaning to the occurrence of shifting events. The individual, therefore, is provided with a veridical view of his/her world and with a means of encouraging and maintaining effective control 
in that world. The extent to which the individual effectively utilizes the attribution process in order to have a reality orientation to the world and a control orientation is contingent upon several factors. The author considers two which are central to this study: multiple attributions and attributions made without guilt.

When one considers the basic assumption of the individual as an open system constantly changing and affecting change in others through the interaction of input and output of energy or messages due to the inherent qualities of interrelationships between and interdependence of all systems (Watzlawick, Beavin \& Jackson, 1967, p. 127; A11port [Buckley], 1968, p. 345), the importance of attributing responsibility to more than one factor is apparent. In other words, because of the very nature of the cosmos, things and people do not exist in isolation. Therefore, it is highly unlikely that one thing or one person is responsible for a cause to a particular event. This is certainly evident in a couple relationship. In fact, Kelley (Jones et al., 1972, p. 1) states that a special feature of a social interaction is that each participant is both a causal agent and an attributor. One's own behavior may be one of the causes for a particular behavior one is trying to understand and explain. Moreover, external causes (contextual factors) are equally important in understanding events (Jones \& Nisbett [Jones et al.], 1972, pp. 93-94). Indeed, more cognitive effort is needed in seeking further and possibly better explanations (multiple causes) to unitary events (Kanouse [Jones et a1.], 1972, p. 131).

Guilt is a chronic tendency whereby the individual blames oneself for, or projects onto others, the violating or failing to attain 
internalized standards of proper behavior (Mosher, 1965, p. 162). Standards for proper behavior, encompassing internalized prohibitions (should not's) and internalized valued goals (ought to's), are intimately related to the integrity of the individual (Mosher, 1965, p. 162; Branden, 1969, pp. 125-126; Brenner, 1957, pp. 134-135). Consequent1y, if certain misdeeds are committed or achievements not attained, there is an accompanying moral conviction that the wrongdoing "should not" have been committed or that the particular goal "ought to" have been attained. The individual is rigidly fixed with standards of proper behavior, that to have transgressed these standards by oneself or others, means that whoever was responsible, not only did a terrible thing, but also is a terrible person: incompetent to live or even unworthy of living. Therefore, the individual, with guilt, is so immobilized that positive action cannot be taken in order to correct the wrongdoing, redefine certain goals better suited for his/her capacities, or re-evaluate the standards of behavior.

The reason projected guilt on to others can be incapacitating, as well, is because the guilt continues to be with the individual in some form (Horney, 1937, p. 246). The following illustration may serve to explain the dynamics of projected guilt: when the individual is hurting from the guilt for not obtaining a particular goal, blaming another serves to do something about that hurt (guilt) with the hope of alleviating it (Tanner, 1973, pp. 34-35). However, the individual continues to have the feelings of guilt because it is the individual's own standards which have been transgressed. Hence, the consequential sequellae of guilt can be manifested. 
The development of guilt occurs during childhood when parental values are incorporated out of fear of disapproval, punishment, rejection, withdrawal of love, and any other disciplinary measure (Gardner, 1970, pp. 125-126). If the parent/child relationship is based on authority, criticism tends to be forbidden because it would undermine the authority. Under such a condition, the child does not venture to think the parents may be wrong. The child feels, however, someone must be wrong, and thus comes to the conclusion that it must be he/she who is at fault. The process is an emotional rather than a cognitive one. It is determined out of fear, not by thinking (Horney, 1937, pp. 248249).

As the child develops, other authority figures who are empowered to punish for wrongdoings are encountered so their values tend to be incorporated as well (Gardner, 1970, p. 126). Yet, another child who is less intimidated by others may go through a more discriminating process: reject some values of others, incorporate certain values of others, and formulate still other values which then all become largely his/her own. It is these internalized standards from whatever source (parents, society, God, and/or one's own) which influence thoughts, feelings, and behavior and which contribute to the person's integrity (Arieti, 1967, pp. 149-150).

When a discrepancy arises between internalized standards and external behaviors, a critical point has been reached by the individual. If the individual holds fast the internalized standards, feels intense conflict over external behavior (misdeed) in relation to the internalized standards, and berates self to such a degree that no constructive 
action is taken, then the person experiences guilt.

Divorce is characterized in the literature as a hazardous life event which induces a crisis (Holmes \& Rake, 1967, p. 218; Wiseman, 1975, p. 205; Goode, 1964, pp. 92-93). Caplan (1964, pp. 38-41) describes a crisis as a period of threat to the individual, thereby severely challenging the continuation of the individual's present way of organized living. The usual coping behavior, which includes problem solving processes and defense mechanisms, is no longer effective; consequently, tension rises within the individual because of the devastation by this dramatic change. Accompanying this rise in tension, the individual experiences feelings of helplessness and ineffectiveness, along with disorganized functioning. In order to cushion this devastating blow, some degree of shock, disbelief, and denial usually manifests itself.

Gradually, as the denial syndrome diminishes the individual becomes more aware of what actually has occurred and the implications for the future. At this point, one begins to wonder why this dreadful event has happened and struggles to identify a reason or sense of purpose and meaning. Answering these questions, lays down the groundwork for reorganization.

Caplan (1964, pp. 53-54) states that the interplay of internal forces (psychological: problem-solving ability, constructive defense mechanisms, view of reality, etc; physical: nourishment, rest, etc.) and external forces (environmental: relationships with others, social and religious attitudes, economic situation, etc.) affect the reorganization of the individual toward either positive or negative resolution. 
A positive resolution is characterized by effective coping behavior resulting from the interaction between the person's favorable internal forces and favorable external forces. More specifically, tension decreases within the individual so that functioning is resumed to the same level or higher level than prior to the crisis. Activities of daily living are resumed in maintaining physiological needs (rest, nutrition, shelter, sexuality) and psychological needs (acceptance of self, assertion, expression of feelings, intimacy with others). These needs are met by the individual alone or with the help of interpersonal and/or community resources (Rapoport [Parad], 1972, pp. 26-29).

A negative resolution is characterized by ineffective coping behavior resulting from the interaction between the person's unfavorable internal forces and unfavorable external forces. More specifically, tension continues within the individual so that functioning is at a lower level than prior to the crisis. Since activities of daily living are not adequately resumed, some of the physiological and psychological needs are not met by the individual nor is this individual able to seek interpersonal and/or community resources in helping meet those needs.

In summary it seems that: (1) if experiencing guilt immobilizes one to such an extent that constructive action is not taken because it is thought one is such a terrible person; and (2) if one thinks one is a terrible person, it is unlikely for that person alone, or unlikely for that person to enlist the aid of others, to help meet his/her psychological and physical needs which are essential for effective coping; and (3) if divorce is a crisis requiring the meeting of psychological and physical needs to cope effectively or resolve the crisis positively; 
then, those individuals who experience guilt will tend to cope ineffectively in resolving their divorce crisis.

Conversely, the same logic would follow for those individuals who do not experience immobilizing guilt. They would tend to cope effectively in resolving their divorce crisis.

Moreover, for those individuals who do not experience guilt, it seems that: (1) if making multiple attributions of responsibility reflects more careful thought and a greater reality orientation to the world; and (2) if favorable internal forces (problem-solving ability, reality perspective) are important contributions for effective coping (positive resolution); then, those individuals who make multiple attributions are more likely to have an even higher level of positive resolution than those individuals who make single attributions in the absence of guilt.

Conversely, the same logic would follow for those individuals making multiple attributions in the presence of guilt. They would tend to cope at a better level (even though they are resolving their divorce crisis negatively) than those individuals who make a single attribution in the presence of guilt.

This concludes the foundation upon which the study was based. The remaining chapters focus on reviewing the literature pertinent to this study, presenting the methodology which explains how the study was conducted, reporting the results of the study, discussing the meaning of the results, summarizing the entire study, and presenting its conclusions and its implications. 


\section{CHAPTER I I \\ RELATED LITERATURE}

The review of the related literature focuses on the phases of divorce crisis: disorganization and resolution. In addition, it explores those forces which the author believes contribute most to divorce resolution: the internal forces of guilt and attribution of responsibility and the external forces of sociocultural attitudes, legal system, economic condition, religious views, and relationships with friends and family. Following each sub-section, the summary of the related literature is connected with the theoretical framework underlying the study.

\section{Divorce as a Crisis}

Disorganization. The impact of divorce is usually so upsetting that few individuals move through it without experiencing some difficulty and pain. Perhaps Bohannon (1971) poignantly sets it into perspective:

One of the reasons it feels so good to be engaged and newly married is the rewarding sensation that out of the whole world, you have been selected. One of the reasons that divorce feels so awful is that you have been de-selected. It punishes almost as much as the engagement and the wedding are rewarding. (p. 33)

During the initial phase of the crisis, the individual can experience much disruption and disturbance in living. In one of the earliest and most basic studies on divorce, Goode (1956) collected data on 425 divorced women in Detroit, Michigan. His findings indicated that 
$63 \%$ of his subjects had experienced at least three of the following personal traumas: difficulty sleeping, increased smoking and drinking, poorer health, greater loneliness, low work efficiency, and memory difficulty. The remaining percentage experienced anywhere from none to one $(p .186 \mathrm{ff})$. Since he relied upon survey interviews years after the divorce, the reports might have been understating the distress. Hence, the percentage of subjects and the amount of trauma might we 11 have been greater.

Concurring with Goode's findings were members of the helping profession (Krantzler, 1973, p. 99; Fisher, 1974, pp. 27-29; Kessler, 1975, pp. 20-40; Gettleman and Markowitz, 1974, pp. 54-59) who have encountered divorced men and women with similar experiences.

In addition to these difficulties, Weiss (1975, pp. 48-82) has reported that most of the men and women attending his Seminars for the Separated in Boston, Massachusetts experienced anger and rage toward the ex-spouse, intense discomfort and anxiety, severe depression, loss of self-confidence, decreased appetite or compulsive nibbling, feelings of desolation, and disruption of identity. To a lesser extent, some of the individuals reported euphoria connected with the new sense of freedom, greater opportunities opening up to them, and increased self-confidence and self-love. Weiss attributed this to a relief in feeling the ex-spouse was not needed after all, but concluded, due to the fact that these euphoric feelings were usually not lasting, they were not fully integrated into the personality. Others (Bohannon, 1970, p. 33; Steinzor, 1969, p. 27) have discovered that emotional mood swings from sadness to euphoria were very common. Perhaps these euphoric feelings 
can best be explained as analogous to denial periods which have been heretofore mentioned in the theoretical framework. They may be the unconscious way that the overwhelmed person gets temporary relief during the phase of severe disorganization.

Other frequent reactions were guilt, a sense of failure, and attributing the responsibility to the ex-spouse for the marriage terminating (Steinzor, 1969, pp. 22-23; Weiss, 1975, pp. 14-24; Fisher, 1974, pp. 29-30; Hetherington et a1., 1976, p. 13). In fact, Kessler (1975, p. 107) found in her survey of seventy persons who came to the Georgia State Counseling Center that $99 \%$ had strong feelings of failure in being able to sustain a marriage.

The most recent comprehensive and well designed longitudinal study was completed by Hetherington et al. (1976) who used a multimethod, multimeasure approach to examine the effects of divorce on parents and their children two months, one year, and two years after the divorce. Forty-eight divorced parents and their nursery school children (equal numbers of both sexes) from the general population in Virginia and forty-eight intact parents and their nursery school children (equal numbers of both sexes) comprised the study.

In addition to the disturbances already cited, Hetherington et al. (1976, pp. 9-10) found there were significantly more stresses in practical problems of living related to household maintenance in divorced families than in intact families. Many (77\%) divorced men, especially from those marriages in which conventional sex roles had been maintained, reported distress in having difficulty coping with household tasks: shopping, cooking, laundry, and cleaning. Even divorced 
mothers and their children had difficulty with routine tasks and regular scheduling of events: they were less likely to eat dinner together, bedtimes were more erratic, and children were more likely to arrive at school late.

One of the most marked changes in divorced parents was their decline in self-esteem. They felt they had failed as parents and spouses and expressed doubts about their ability to adjust well in any future marriage. In addition, $75 \%$ of the divorced fathers reported that they felt they were coping less well at work (p. 13).

In the area of relationships between divorced partners, $66 \%$ of the exchanges involved conflicts over finances and support, visitation and child rearing, and intimate relations with others. Moreover, the relationships between all but four of the divorced couples were characterized by acrimony, anger, feelings of desertion, resentment, and memories of painful conflicts. However, these relationships were tempered by considerable ambivalence: $71 \%$ of the mothers and $60 \%$ of the fathers reported that in case of a crisis the ex-spouse would have been the first person to be called (pp. 17-18).

Another recent but 1 imited longitudinal study (Wallerstein \& Kelly, 1976, pp. 256-269) designed to observe and record the impact of divorce on each family member shortly after the initial parental separation (one parent had taken legal action in filing for divorce) and again one year later, was conducted in a suburb of Northern California. Their major finding in the initial responses of the children, 8-10 years of age, after separation included intense conflicting feelings and fears. They found these children tried to give coherence and continuity to the 
baffling disorder which was experienced; yet, they perceived the turbulence and disruption with soberness and clarity. These findings greatly differed from reports (Kelly \& Wallerstein, 1976, pp. 20-33) which indicated that children aged 5-7 were disorganized and immobi1ized by worry and grief.

In summary, the literature lends empirical support to the theoretical contention that divorce is a crisis characterized by the initial stage of disorganization. Varying degrees of problems are experienced: increased tension and discomfort, difficulty with household tasks, inefficiency at work, interpersonal troubles, and decline in self-esteem.

Resolution. Following the initial phase of the crisis, the individual moves toward resolution. The length of time of this movement from disorganization toward resolution has not been clearly defined for divorce. However, Caplan (1964, p. 525) maintains that for most crises, the maximum duration is four to six weeks.

In any event, due to the lack of sufficient systematic research on how individuals are resolving their divorce crises, the time sequence can only be calculated from the research which has already been done. And as has been previously mentioned, Hetherington et al. (1976) have conducted the only substantial longitudinal study from which they conclude that the height of the crisis takes place within the first year after divorce. In fact, at one year after the divorce, $60 \%$ of the fathers and $71 \%$ of the mothers reported they thought the divorce might have been a mistake, they should have tried harder to resolve their conflicts, and they felt the alternative life style was not satisfying. 
This percentage did decrease by the end of the second year: $18 \%$ of the fathers and $25 \%$ of the mothers (p. 18).

At the end of two years, many of the differences between divorced and intact families in the area of self concept and emotional adjustment diminished. However, some findings revealed that divorced parents continued to have lower self-esteems and emotional adjustment problems. This was found to be the case in divorced mothers, particularly those of sons, who felt more anxious, depressed, angry, rejected, and incompetent. Also, divorced parents scored lower on the socialization scale of the California Personality Inventory and the Personality Scale of the Adjective Checklist. Moreover, divorced parents who were older and who had been married the longest had the greatest negative change in self-concept (pp. 11-12).

Even though happiness, self-esteem, and feelings of competence in heterosexual behavior increased steadily for divorced parents over the two year period, they were not as high as for intact parents. However, intimacy in relationships for divorced men and women showed a strong positive correlation with happiness, self-esteem and feelings of competence in heterosexual relationships, as well as for intact parents. Furthermore, subjects who later remarried and shifted from this study to a step-parent study, scored as high on happiness but lower on selfesteem and feelings of competence as did intact parents ( $p$. 16).

Some interaction patterns between divorced parents and children differed significantly from those in intact families. Divorced parents made fewer maturity demands of children, communicated less well, tended to be less affectionate, and showed marked inconsistency in discipline 
and lack of control over their children. These differences were greatest during the first year after divorce, with a lowering of the differences by the end of the second year. However, even at this time, poor parenting by divorced parents continued, particularly by parents of sons but greatest by mothers of sons (pp. 20-24). Likewise, children of divorced parents exhibited more negative behavior than did children of intact families, but it diminished markedly over the two year period, except in boys (pp. 25-26). These poor parenting practices correlated with undesirable and coercive behavior in children, particularly in divorced mothers and sons (p. 29).

A most significant finding was that low self-esteem, feelings of incompetence as a parent, and anxiety showed correlation with children's aggressive and noxious behaviors (p. 29). Moreover, effectiveness in dealing with the child was related to support in child rearing from the spouse and agreement with the spouse in disciplining the child in both divorced and intact families. When support and agreement occurred between divorced couples, the disruption in family functioning appeared to be less extreme and the re-stabilizing of family functioning or positive resolution occurred by the end of the first year. Also, when there was support in child rearing, a positive attitude toward the spouse, low conflict between the divorced parents, and when the father was emotionally mature, frequency of the father's contact with the child was associated with more positive mother-child interactions and with more positive adjustment of the child (pp. 31-32).

In summary, the literature lends empirical support to the theoretical contention that following the initial phase of disorganiza- 
tion in the divorce crisis, there is reorganization and movement toward resolution (positive or negative) through the interaction of favorable internal forces of the individual and favorable external forces of the environment. This has been evidenced by aforementioned findings:

parents coped better (positive resolution) when having experienced intimacy in heterosexual relations (favorable external force), support and agreement from ex-spouse (favorable external force), and/or desirable behavior in children (favorable external force) which influenced or was influenced by high self-esteem (favorable internal force); and the reverse was true for parents who coped worse (negative resolution).

In addition, the literature lends empirical support to the theoretical notion that the individual is an open system constantly changing and affecting change in others through their interaction by virtue of their interdependence and interrelationships. This has been demonstrated in the prior findings: ex-spouses changed and affected change in each other through their interactions between each other, between their children, and/or between their friends.

\section{Internal Forces on Resolution of Divorce Crisis}

Guilt and attribution of responsibility. Although there are many internal forces which can influence the outcome of the divorce crisis, the author will only focus on those most pertinent to this study.

It has been already cited in the previous section that strong feelings of guilt and attributing the responsibility to the ex-spouse for the marriage terminating are often experienced by the divorced (Steinzor, 1969, pp. 22-23; Hetherington et al., 1976, p. 13; Weiss, 
1975, pp. 14-24; Fisher, 1974, pp. 29-30; Kessler, 1975, p. 107). However, there has been no investigation of these variables on the resolution process in the divorce literature. In addition, the strong feeling of guilt which has been previously cited is suggestive of a temporary reaction as opposed to the meaning of guilt which is being investigated in this study: the chronic disposition in one's personality.

In the social psychological literature there have been numerous studies enlarging on the body of knowledge in attribution theory which is concerned with the cognitive process of attributing causal sources to events so that the individual can understand and respond to them (Kelley, 1967). Even though most of these studies have been done under the rigors of experimental laboratory design, some are relevant to this study and warrant a review.

Dies (1970) investigated the relation of need for social approval (as measured by Marlowe-Crammer Social Desirability Scale) to attribution of responsibility. When dyads working on a cooperative task and exposed to induced failure, approval-dependent persons were more likely to rationalize or excuse "failure" by attributing the responsibility to various experimental factors and/or their partners as cause for the task not working in anticipation of disapproval and threat to self-esteem.

A study by Hochreich (1975) focused upon the relationship between attribution of responsibility and two groups of individuals: (a) internals--individuals who perceive reinforcements as the result of own behaviors and characteristics, and (b) externals--individuals who perceive reinforcements as the result of forces beyond control, i.e., luck, 
fate, or influence of powerful others. There were two subgroups of externals: defensive externals, whose externality is presumed to reflect primarily a verbal technique of defense, and congruent externals, whose externality reflects a more genuine belief that most outcomes are determined by forces beyond their personal control. It was found that defensive externals showed a stronger tendency than did congruent externals and internals to resort to attributing the responsibility to another following failure at achievement tasks.

Both these experimental laboratory designed studies yield findings which demonstrate that particular attributions of responsibility are indicative of certain personality patterns. Individuals faced with a failure and either need social approval or tend to perceive themselves as helpless usually attribute the responsibility for the failure occurring to the other person or external factors. Although these findings may not have direct application to resolving a crisis, it does shed some light on what might be the characteristics of or what might be going on with a person who attributes responsibility to another (e.g., to ex-spouse) in a dyad situation which failed (e.g., termination of a marriage--divorce).

Some field studies on attribution of responsibility, crisis resolution, and guilt provide pertinent data. Bulman and Wortman (1976, p. 25) examined the relationship between attributions of responsibility and crisis resolution for individuals who suffered the severe misfortunes of paralysis following an accident. The results indicated that attributing the responsibility to another for the accident occurring correlated with resolving the crisis negatively; yet, attributing 
the responsibility to themselves correlated with resolving the crisis positively. The investigators suggested that perhaps control issues were involved in these results. They reported that those individuals who made attributions to another possibly expressed a feeling of helplessness and non-control in the situation. Some remarks made by these individuals which led the investigators to this conclusion were: "I wish I sat up in the seat. . . . I would have grabbed the wheel" and "I was changing a tape in the car and then looked up and saw the detour; but, it was too late for me to do anything" (p. 27). Conversely, it was reported that those individuals who made attributions to themselves saw the accidents as following logically and inevitably from their own behavior, a behavior that was freely chosen and enjoyed. They had some control in the situation.

This feeling of control might be connected with the conviction of one's own efficacy, the acknowledgment of one's own agency; hence, the individual is capable of responding in one's own behalf and is more likely to positively resolve a crisis. The feeling of helplessness, on the other hand, might be connected with a denial of one's own agency; hence, the individual is unable to respond in one's own behalf and is more likely to negatively resolve a crisis.

Chodoff, Friedman, and Hamburg (1964, pp. 745-749) described the relationship between attributions of responsibility and crisis resolution for parents of fatally-ill children. It was found that those parents who attributed responsibility to themselves and those parents who attributed responsibility to others (e.g., nurses, physicians) for their children becoming $i 11$ resolved the crisis positively. The re- 
searchers related this to the persistent and urgent need by the parents to understand the tragic event. That their child had been stricken at random was difficult to accept. Attributing the responsibility to themselves or another helped them cope with the crisis positively.

These results differed with those from the Bulman and Wortman study insofar as attribution to another is also linked with positive resolution in the Chodoff et a1. study. This discrepancy might be due to these investigators not exploring the full dimension of resolution crisis. Although they point to the persistent and urgent need by the parents to understand the tragic event through making the attributions of responsibility in order to resolve the crisis, the crisis literature (Caplan, 1964, pp. 38-41) identifies the "urgency to understand" as laying down the groundwork for reorganization. Therefore, what was identified in the Chodoff et al. study as positive resolution might have been better described as only the beginning stage of resolution and not full positive resolution. Consequently, the full outcome of resolving the crisis by the parents might have been different if this study were done after more time had lapsed from the onset of the crisis.

Abrams and Finesinger (1953) examined guilt and its relationship to crisis resolution of cancer patients and their families. The results indicated that guilt was linked with the outcome of negative resolution which included certain behaviors and feelings: patient's delay in seeking medical attention; feelings of inadequacy, inferiority, dependency, and rejection; and inhibiting patient's ability to communicate.

Although there is some ambiguity in the Chodoff et al. study, 
the previous field studies lend some empirical evidence to the author's assertion that guilt is linked with negative crisis resolution and attributions of responsibility are linked with various levels of crisis resolution.

A detailed case study presented by Skilbeck (1974) illustrated the crucial role attributions of responsibility can play in the development and resolution of a crisis. The client attributed responsibility to her apparent inner psychopathology as cause of a crisis and reacted further in an emotionally disturbed way. With the help of the therapist, all the factors relating to the crisis were examined carefully, and the inner psychopathology was reattributed to the appropriate external cause (upcoming exam). As a result, the patient began to cope more constructively in resolving the crisis.

This study clearly exemplifies how an attribution of responsibility to self and an attribution of responsibility to external factors can be linked with the resolution of a crisis. It also demonstrates the importance in looking objectively at all the factors impinging on the crisis, so that attribution of responsibility to inappropriate causes does not have a harmful effect on the resolution. Moreover, this study shows the influential nature of external factors, i.e., the therapist. With his guidance, the client was able to reattribute the cause to the appropriate source. Caplan (1964, p. 54) found that during crisis the individual is more susceptible to the influence of others than during periods of stable functioning.

In summary, the literature lends more empirical support to the author's contention that guilt is related to maladaptive coping behav- 
ior (negative resolution). In addition, there is empirical evidence that certain attributions of responsibility are related to various levels of crisis resolution.

\section{External Forces on Resolution of Divorce Crisis}

There are a multitude of external forces which can influence the outcome of the divorce crisis; however, the author will only focus on those which seem particularly pertinent. It should be noted, also, that these forces do not operate in isolation, but rather are interrelated. However, for clarity they will be explored separately. Furthermore, it must be pointed out that ultimately in resolving the divorce crisis it is the interaction between the external forces of the environment and the internal forces of the individual that resolve the crisis negatively or positively.

Sociocultural. Transforming social attitudes toward divorce are becoming more evident. Repugnance and displeasure are giving way toward looking at divorce as a reasonable alternative to an unhappy or unfulfilling marriage (Bernard [Bohannon], 1970, p. 10; Norton \& Glick, 1976 , p. 12). However, there continues to be undercurrents in our society of confusing and contradicting values and beliefs which make it difficult to get divorced and/or be divorced.

Firstly, it is more costly to be divorced than to be married (Brockway, 1973). Throughout the country, the very least one can pay for a divorce is the court fee (excluding lawyer's fee) which is at least three to five times as much as the minimal cost to be married 
(including marriage license and blood tests). Moreover, it takes longer to be divorced than to be married (Brockway, 1973). Usually, to procure a divorce, one files for a hearing which takes at least two weeks to schedule; after the hearing, six months must pass for the divorce to be official. To be married, one merely has to have the results of a blood test, which can take two to four days, and find any available justice of the peace, which can be most immediate. These obstacles in getting a divorce can add unnecessary stress to an already stressful situation.

Kessler (1975, pp. 160-162) considers the fact that divorce is not institutionalized as another way of society discriminating against and punishing the divorced. One moves from a very structured, strictly defined, fully institutionalized marriage to divorce where few ideals or expectations are found. Some of the consequences of this are apparent: parental status is clouded for those who do not have custody of children; continued relationships with ex-spouse and with families of origin of ex-spouse are questioned; relationships with immediate families of remarried ex-spouse are under scrutiny; creditors, employers, and country clubs sometimes have unfavorable views of the divorced; and friends and relatives don't know how to react. There are no rituals connected with divorce as there are in other major life events: birth, marriage, and death. This lack of ritual and formalized communication seems to convey not fully accepting the event.

The confusion about and the problems of the continued relationships among the children and parents and their extended families are explicated by Margaret Mead ([Bohannon], 1970, pp. 120-121): 
. . our present attitudes toward divorce and remarriage come from our refusal to treat the conception and production of a child as an unbreakable tie between the parents, regardless of the state of the marriage contract. In most societies, the permanency of the consanguinous tie between a child and its forbears, including the siblings of parents and grandparents, and their offspring, is taken as a matter of course. - People still seek for relatives in other countries. But our present divorce style often denies the tie between the child and one of the parents, and it permits the parents to deny that--through their common child--they have an irreversible, indissoluble relationship to each other. Where one parent can be declared as grievously at fault, all may be denied him or her. And custom follows law in that, in many bitter divorce battles, one parent is "de facto" denied any contact with his or her own child, and both parents are allowed and often required by custom to completely break any contact with each other.

Another prevailing attitude which can be problematic for the divorced is that marriage is prized as the emotional unit from which adults derive the ultimate reward of personal satisfaction and fulfillment (Feldberg and Kohen, 1976, p. 158) and for which children attain the necessary nurturance for sustenance of life (Ackerman, 1969, pp. 119-120). Even social life (entertainment and recreation) among adults revolves around couples and/or their families (Barnhill, 1975, pp. 5-7). Divorce, then, is regarded as a failure in not having maintained this goal of marriage and as an index of social disorder along with suicide, homicide, narcotic addiction, alcoholism, and crime (Mead [Bohannon], 1970, p. 124).

This notion that divorce is a failure can possibly lead to viewing the divorced person as having failed in some way. More damaging, however, is if this notion leads to viewing the divorced person as a complete failure. In any case, whether or not the person views the divorcee as having failed in some way or more deeply as having failed com- 
pletely, there is societal pressure on him/her not to remain divorced. It is a deviant state and one which is not beneficial to his/her emotional and social well-being and one which is not conducive to proper child rearing. The divorced person, then, may tend to rush into remarriage, since marriage is the reference group and re-entry becomes the task, without looking realistically at what happened in the previous marriage and learn from it in order to prevent another crisis to develop.

An interesting study was done by Hill, Rubin, and Peplau (1976) from which they assessed the difference in reactions of unmarried couples who dissolve their relationships and married couples who dissolve theirs. They found that breaking up before marriage was less stressful than marital breakups which they contended reflected a fundamental difference between the social-psychological contexts of premarital breakups and divorce. They deduced that breakups before marriage take place in the context of the dating system in which coupling, uncoupling, recoupling are approved and accepted elements. On the other hand, they saw marital breakups as a counter-normative phenomenon which is often stigmatized by kin and the community.

Contrary to the common negatively held social attitudes toward divorce, there is a small but growing movement toward pluralism. Although not fully ingrained in our culture, alternate forms of marriage and life style are being experienced and receiving attention (Rossi, 1972).

Largely through the influence of the feminist movement, women are pooling their resources in self help groups to aid divorced women 
with legal, therapeutic and child care services; and on counseling for job opportunities and welfare rights (Barnhil1, 1975, pp. 8-9). In addition, the value and relevance of the family is coming into question (Cooper, 1970).

In spite of these recent changes, the literature generally supports the author's view that prevalent sociocultural attitudes are mostly unfavorable external forces in that they view divorce as an enemy of marriage and the family making it inherently unacceptable since divorce does not maintain these institutions. Furthermore, the negative attitudes connote having failed at these favored institutions which can have a harmful affect on one who is struggling with divorce.

Legal. Two law professors, Goldstein and Gitter (1970, pp. 12-15), and a practicing attorney, David Cantor (1970, p. 10) who has published on moral issues and the law, consider legal concepts from which divorce decrees are granted to be archaic and illogical and to cause incalculable damages on divorcing spouses and their children. The primary concept ruling most of the American decrees is the one based on fault. They maintain that divorce is granted only upon showing in court that the defendant spouse has committed an offense against marriage which tends to exacerbate aggressive forces that may be already undermining the family.

No degree of kindness or civility or generosity on the part of spouses can avoid the necessity of assuming the posture of combatants and at least performing superficially like antagonistic gladiators. The process of battle for those who seek it is because of the fault concept and the adversary system, rich in ways to traumatize, impoverish and enrage spouses; in ways to delay decisions and cripple children; and, if used to the most 
disgusting limits, in ways to defeat the divorce and thus maintain in law marriages which are dead in fact. (Cantor,
1970 , p. 11)

Cantor maintains that truly uncontested hearings are rare and that those which appear to be uncontested have had prior negotiations and bargaining. The price for an uncontested hearing can center around highly charged emotional issues: alimony and/or support payments, custody of children, visitation rights, and division of joint assets. Furthermore, these issues are not determined on objective fairness, but rather on the basis of the plaintiff's desperation which leads to much hatred, bitterness, and resentment (p. 11).

In addition to the emotional resources being drained, financial resources are diminished as we11, due to high lawyer's fee and/or detective charges (Goldstein \& Gitter, 1970, p. 14). Hence, these resources can have a negative effect on the post divorce relations between spouses and between spouses and children. As Goldstein and Gitter succinctly phrase it, "laying blame can undermine the development of sound reorganized family relationships" (p. 14).

There have been some minor breakthroughs in reforming the granting of divorce: "no fault" divorce (Cantor, 1970, p. 12), "do it yourself" divorce (Barnhill, 1975, p. 4), and free legal aid services (Barnhi11, 1975, p. 9). The "no fault" divorce, which, according to a 1974 report, has been instituted in twenty-four states (Norton \& Glick, 1976, p. 12), eliminates the necessity of placing blame on the spouse; however, a hearing still has to occur which means high legal payments. Besides the financial burden, appearing in court does a certain violence to the integrity of the spouses concerned because the decision to dis- 
continue their own marriage is out of their hands. Cantor (1970, p. 12) and Brockway (1973) believe it is arrogant for the state to intrude with its monopolistic power to decide whether or not a marriage should continue.

Books have been published explaining how to represent oneself in getting a divorce. Although this has the advantage of eliminating the high cost of lawyers, one has to have enough self-presence to understand and properly execute the complicated legal procedures. This is an unlikely task for many of whom are experiencing the turmoil of crisis.

The free legal aid services are reserved for only those who can prove they are impoverished--meet the acceptable HEW guidelines (Norton $\&$ Glick, 1976, p. 12). However, in some of the legal aid centers, divorce matters are not considered a priority and/or are looked upon with disfavor because of the involved procedure (Brockway, 1973). Therefore, one might not be able to obtain legal aid even though one might meet the requirements. If one is fortunate to be able to obtain legal aid, one usually needs perseverance (an unlikely asset during crisis) to weather the long waits and inefficiency which often characterizes such bureaucratic free services.

The literature supports the author's view that the legal system, as it is now, can have a negative effect upon the resolution of the divorce crisis insofar as it is an unfavorable external force because of the concept of fault and its consequential effect on the relationships among family members. The additional procedural difficulties and/or financial burden also affect the resolution. 
Economic. Hetherington et al. (1976, pp. 10-11) found that most individuals encounter economic difficulty following divorce and was one of the main sources of disagreement between divorced couples. They found that even though the average income of the divorced family equaled that of the intact family, problems arose associated with maintaining two households. In an attempt to raise their income, divorced fathers were more likely than married fathers to increase their work load. This created some duress in the first year following divorce when many fathers were feeling immobilized by emotional problems and unable to work effectively.

It has been found (Barnhi11, 1975, pp. 8-9; Kessler, 1975, pp. 165-170; Goode, 1956, pp. 183-195; Waller, 1967, p. xx) that women faced particular hardship following divorce because of their reduced economic status. They maintained it was especially so for women who had not been employed during their marriage and/or who had to take care of children. (This would be applicable to men, as well, whose numbers have increased in gaining custody of their children and/or who have not worked during their marriage.) In fact, the study done by Blair (1969, p. 74) of 65 divorced women in Florida reported that adjustment was significantly more difficult for divorced women who had inadequate financial support for themselves and/or their children.

It seems likely, then, that if one is struggling with providing the basic essentials of food and shelter, little energy would be directed toward other fulfillments of 1 ife, i.e., personal and interpersonal development, especially when one is trying to reorganize one's life. As Galbraith (1964, p. 117) says, "In the poor society, not only 
do economic considerations dominate social attitudes but they rigidly specify the problems that will be accorded priority."

The literature supports the author's view that the economic condition of the divorced person, as an external force, influences positively or negatively the resolution of the divorce crisis depending on what the economic condition is.

Religious. The majority of people in the United States have been strongly influenced by Christianity. It is important, then, to gain some understanding of the Christian perspectives and beliefs about divorce and marriage. Norskov 01 sen (1971, intro.) says that our "current Western views on divorce are heavily influenced by the New Testament and its interpretation by the Christian Church."

The Roman Catholic Church's views have been largely based on the teachings of St. Augustine and St. Thomas Aquinas who saw marriage in terms of procreation, faithfulness, and a sacrament. The purpose of marriage was to produce children in an exclusive bond of faithfulness to God (01sen, 1971, p. 2ff). Only adultery could be a basis for breaking the bond, but this did not mean one would be free to remarry. Since marriage was considered a sacrament, it was undissolvable (p. 4ff). One could only remarry if the spouse died. In spite of these teachings of Augustine and Aquinas, the Roman Catholic Church does recognize an annulment which is a form of divorce. This can only be granted by proving the marriage has initially been unlawfully contracted (p. 18).

Martin Luther, as the voice of the early Protestant reformation, aid not agree with the Roman Catholic Church's doctrine of marriage as 
a sacrament. Even though he had a high regard for marriage and agreed that its primary function was for procreation, he did believe there was justification for terminating marriage. According to 01 sen (1971, p. $44 \mathrm{ff}$ ), Luther suggested four reasons for ending a marriage: adultery, ignorance of a former contracted marriage, desertion, and a wife's refusal to "render the conjugal duty."

Luther's views were expanded and modified to some extent by Bullinger, Calvin and Milton who influenced the resulting stand on marriage and divorce taken by the Protestant Reformation Churches. Heinrich Bullinger expanded the functional view of marriage and asserted that it was for companionship, too. In fact, he considered the husband and wife should be of one mind, disposition, and temper ( $p .73)$.

John Calvin, conservative in his attitudes toward divorce, influenced a significant sector in restraining divorce. He considered the following grounds for divorce: adultery, impotence, extreme religious incompatibility, and desertion. In addition, Calvin did not contest the death punishment for adultery which was practiced in Geneva at the time (p. 99). He also believed procreation and protection against fornication to be the primary purposes of marriage (p. 100).

John Milton saw the purpose of marriage as fulfillment of love and helpfulness $(p .132 f f)$. Since he believed the mental pressure of incompatibility could be a danger to a person's health, he concluded that divorce be granted for such circumstances ( $p$. 133). He also believed divorce did not prevent remarriage (p. 136). Although Milton's views were never formally adopted by any official church body, they have strongly influenced Protestant Christian attitudes and social laws re- 
garding marriage and divorce ( $p .136 f f)$.

These six church leaders four hundred years or more ago continue to have their impact on some of the prevailing attitudes about marriage and divorce today: marriage exists for children and as an expression of interpersonal love and companionship, and divorce is an act of faithlessness toward God and partner and exists as a release for not fulfilling interpersonal love and companionship. One can extrapolate from these attitudes the notions that marriage is important for child rearing and personal happiness and that divorce represents a void which can be only filled by marriage. Consequently, divorce is not looked upon so favorably and seems to indicate that one of the spouses committed some wrongdoing.

Consequently, these negative attitudes toward divorce can have an adverse effect on the resolution of the divorce crisis.

Relationships with friends and family. Of all the external resources available to the divorced, both friends and family are potentialiy the most important. Their presence can be the only real antidote to loneliness (Hunt, 1970, p. 53) and their expressions of understanding and support can help combat feelings of worthlessness and failure (Krantzler, 1973, pp. 90-91).

Hunt (1966, p. 56) has explored the effect of divorce on one's friendship pattern and estimated that $20 \%$ of one's friends severed the relationship because of the divorce. Many of the remaining friends were unsure how to react: some perceived the divorce as freedom and were envious; some were confused or unable to deal with the issues around the 
divorce; some were fearful that their marriage would end in divorce; some were protective of their spouses; and some placed blame on one spouse and remained loyal to the other.

Goode's findings (1956, pp. 166-167) indicated that $60 \%$ of the wife's family and friends had a mild to strong degree of support and were sympathetic to her. The remaining $40 \%$ drifted away.

An extensive study of divorce impact on friends was done by Miller ([Bohannon], 1971, pp. 63-71). He delineated friends had twe lve types of reactions: anxiety, shame, inordinate preoccupations with divorce, desire for a sexual relationship, pleasure over the suffering of the divorced person, feelings of superiority, surprise and incredulity, experience of emotional loss and grief, conflict over allegiances, disillusionment about friendship, crisis about personal identity, and preoccupation and curiosity about the settlement. What people did as a result of a friend's divorce was a direct consequence to the type of feeling reaction they were having.

Barnhil1 (1975, pp. 5-7) pointed out that even if the divorced person was included by friends, the divorced person wanted to leave that friendship group. She found that reason to be based on the fact that discomfort was experienced by the divorced person. That group no longer met the divorced person's needs because it was a couple-organized group. Weiss (1975, p. 145) concurred with Barnhill in the need of rebuilding a friendship network since divorce tended to produce a change in social role. He (pp. 192-193) found that those with adequate selfconfidence began to counteract the loneliness through dating and parties; other, less sure, would more likely join Parents Without Partners 
or some similar group activity.

In the longitudinal study done by Hetherington et al. (1976, pp. 14-15), the social life of the divorced men and women was lower than that of married persons. It was reported that at two months after divorce, married friends were being supportive and considerable time was spent with them. However, these contacts rapidly declined, more so for women than for men. Divorced men and women who had not remarried in the two years following divorce repeatedly spoke of their intense feelings of loneliness.

Families of origin and close ties with other relatives have similar functions and values as those with friends. In general, Weiss (1975, p. 194) found families to be particularly helpful in filling the loneliness gap. However, Goode (1956, p. 151) indicated that families, as compared to friends, were apt to be more disapproving of divorce. He attributed this to their clinging to traditional values for their own members than for their friendship circle. Blair (1969, p. 73) stated that those fathers, not mothers, who had objections to the former marriage, significantly made adjustment more difficult for their divorced daughters.

Putney (1975) has done an intensive case study on fifteen separated/divorced individuals in examining their personal and social relationships. He found that functionally supportive relationships were the core factors in adjustment to marital disruption (p. 224).

The findings of Hetherington et al. (1976) concur with Putney's insofar as intimacy in heterosexual relationships had a greater positive influence on the divorced person's coping than did either unintimate re- 
lationships with friends or relationships with family. The specific coping which was measured was happiness, self-esteem, and feelings of competence. Intimacy was referred to as "love in the sense of valuing the welfare of the other as much as one's own, of a deep concern and willingness to make sacrifices for the other, and strong attachment and desire to be near the other person" (p. 16). They also found that families and close friends (especially other divorced friends) were related to the divorced mother's effectiveness in interacting with her children. This positive relationship was not the same for intact families (p. 32).

The literature supports the author's assertion that relationships with friends and family influence the individual's resolution of the divorce crisis.

In summary, the literature lends empirical support to the theoretical contention that the resolution of divorce is influenced by the interaction of external forces with the individual. There is further evidence that each of the external forces are interrelated.

In addition, there is strong evidence that suggests sociocultural, legal, and religious attitudes view divorce as a wrongful act and as a failure in not maintaining the marriage. Hence, if the divorced individual has been exposed to and has been influenced by this view of divorce to a great degree, then guilt may be a likely consequence. Moreover, the guilt may cause such intense conflict and limit constructive action that the individual may have difficulty in resolving the divorce crisis.

Furthermore, the literature cited in the beginning of this chap- 
ter lends empirical support that other internal forces, namely, attributions of responsibility, are related to various levels of crisis resolution.

This concludes the review of the literature pertinent to the study. The next chapter explains how the study was conducted. 


\section{CHAPTER I I I}

\section{METHODOLOGY}

The presentation of the methodology in this chapter includes the following: the sample--where it was obtained and how the size was determined; the procedure for the collection of data and the statistical methods applied for the treatment of data; and the instruments used to measure the variables--a description and the tests on reliability and validity.

\section{Sample}

The sample consisted of the entire population of persons (700) who were granted a divorce from the Hampshire County Court of Massachusetts during December 1975 through September 1976. The reason for the inclusion of people from this time period (six to seventeen months since their divorce at the time of the study) is that they be in or very close to their resolution phase of the divorce crisis. Hetherington et al. (1976) found that in their two year longitudinal study, divorced people were approaching their resolution of the crisis toward the end of the first year following the divorce.

The sample was obtained from the records of the Probate Court of Hampshire County in Massachusetts. These records, accessible to the public, contained the names of plaintiff and defendant, their addresses, their children's names and ages, the date of their divorce hearing, and 
whether or not the divorce was granted.

Since the study was done by mail and since it was not certain that the addresses from the records would still be current, it was necessary to have the initial sample be as large as 700 to account for any questionnaires which did not reach the subjects and to allow for enough individuals who did not wish to participate.

Of the original 700,170 men and women actually participated in the study. This number of subjects is considered a desired sample size according to reports (Kuntz and Miller, 1973; Nunnally, 1967) which indicated that sample size be estimated from multiplying twenty by the number of variables. In this study eight main variables have been identified.

\section{Data Collection}

Procedure. The original sample of 700 divorced persons was contacted by a letter (see Appendix A, p. 101) from the researcher containing the following information: identified the researcher and gave the reason for the contact; told them where their name was obtained; asked for their participation in the research; informed them of the nature of the research--general purpose, what their participation would entail, length of their time in participating, and anonymity; and told them they would be receiving the questionnaires in the mail within two weeks and that the results of the study would be made available to them.

Three hundred letters were returned in the mail to the researcher because the addresses of the individuals were no longer valid and no forwarding address was given. Therefore, the packet of ques- 
tionnaires (see Appendix A, pp. 102-113) were sent to the 400 remaining in the sample after two weeks had lapsed from mailing the above letter. The packet of questionnaires contained the following: General Information Questionnaire which also included demographic and attribution of responsibility inquiries; Mosher Guilt Inventory which was called Feeling and Attitude Questionnaire; and the divorce resolution scale which was called Task and Experience Questionnaire.

Even though 400 packets of questionnaires were sent to the remaining sample, it is not known how many actually had the opportunitto participate in the study. Although mail does not get lost very often, mail can be left at its destination, not claimed because the addressee moved, and not returned by the new tenants or owners to the post office. It seems possible this might have happened since there seems to be a high mobility rate in the initial sample of 700 .

Statistical method. Multiple regression analysis was used to ascertain which independent variables (guilt; attribution of responsibility to self, to ex-spouse, or to external factors; multiple attribution of responsibility) of which combinations of independent variables (guilt and attribution to self, guilt and attribution to ex-spouse, guilt and attribution to external factors, guilt and multiple attribution) contributed most to the variation of the dependent variable, divorce resolution. An $F$ ratio was the measurement of significance for each hypothes is tested.

Although the above independent variables are the only ones considered in the study, there are other variables which may have contri- 
buted to the variation. The following are some of these: personality of subjects, past history and experiences in living, past geographical locations, and present geographical location. Despite the researcher being aware of these, they were not considered that important and were not part of the data collection. One variable, however, length of time from divorce, was considered to be more potentially important and was used as a control for each hypothesis tested.

\section{Measurement of Variables}

Attribution of responsibility. On the personal data questionnaire subjects were asked to indicate in proportionate amounts what person(s) and/or things and/or events were responsible for their marriage terminating.

Guilt. Guilt was measured by the Mosher Guilt Inventory which is a self-administered true-false questionnaire which purports to measure guilt as a personality disposition (Mosher, 1968, p. 695). In addition to yielding one general guilt score, three other scores of the three subcategories of guilt can also be obtained: hostile guilt, sex guilt, and morality-conscience guilt. To avoid an acquiescent response set, 38 items are scored in a True direction to indicate guilt and 37 items are scored in a False direction to indicate guilt. The possible range of scores is 0 to 126 . The hostile guilt scale is comprised of 28 items and the possible range of scores is 0 to 48 . The sex guilt scale is comprised of 22 items and the possible range of scores is 0 to 36 . The morality-conscience guilt scale is comprised of 25 items and the pos- 
sible range of scores is 0 to 42 (Mosher, 1966, p. 26).

Reliability. Mosher developed the true-false guilt scale (which will be used in this study) and the forced-choice guilt scale from his sentence-completion measure of guilt. The three methods of measuring the three aspects of guilt (hostile, sex, morality-conscience) were examined in a multitrait-multimethod matrix based on 95 college subjects (Mosher, 1966). He reported that the matrix provided promising evidence of convergent and discriminant validity of the three guilt subcategories by the highly significant correlations which ranged from .91 to .66 . Mosher (1966, p. 29) referred to Campbell and Fiske in defining reliability (agreement between two efforts to measure the same trait through maximally similar methods) and validity (agreement between two attempts to measure the same trait through maximally different methods) which supported his contention that the results of the study be viewed as being closer to the reliability end of the continuum than to the validity end.

Validity. Schwartz (1973) administered three measures of each of six traits (locus of control (I-E), extraversion, neuroticism, cultural estrangement, social desirability, and guilt) to 43 male and 57 female college students. Multimethod analysis of the resulting multitrait-multimethod matrix supported the construct validity of the truefalse Mosher Guilt Inventory which Schwartz found measures guilt as a personality trait as opposed to an emotional state. Mosher's guilt scale had a high significant correlation of .81 with a factor concerned with measuring guilt as a personality trait. Whereas with a factor concerned with measuring guilt as a temporary state, Mosher's guilt scale 
had a low correlation of .04 .

Resolution of the divorce crisis. The resolution of the divorce crisis was measured by the author's resolution scale which is a self-administered questionnaire. The 26 items reflect behaviors which indicate self-acceptance, self-assertion, expression of feelings, level of tension, sexuality, relationships with friends and/or children, utilization of resources, and meeting some basic physical needs. Subjects were to indicate on a scale, 1 (never) to 11 (always), the extent to which the statement described them for three different periods: during their previous marriage $(M)$, during their present state now $(N)$, and how they would prefer to feel or behave $(P) .^{1}$ Placing the " $N$ " in the same space as the " $M$ " or in a space which is between an " $M$ " and a "P" would indicate positive resolution which has been defined as functioning at the same level or higher level than prior to the divorce. Likewise, placing the " $N$ " in a space which is closer to the "M" and farther from the "P" would indicate negative resolution which has been defined as functioning at a lower level than prior to the divorce. Scores, which were calculated from the placing of the "M," "N," and "P," were either a positive number reflecting positive resolution or a negative number reflecting negative resolution. Although the author has designed the direction of a positive resolution toward the "11" end of the continuum for fourteen items and toward the "1" end of the continuum for twelve items, there is the possibility for the subject to indicate the direction of positive resolution for him/her by the placing of the "p" (preAppley.

${ }^{l}$ Response procedure was developed in conversation with $\mathrm{Dr}$. Dee 
fer). Therefore, the subject would be protected from the author's bias. Reliability. A split-half reliability coefficient of .65 was obtained from the scores on the resolution scale. This was determined by dividing the items on the scale in such a way as to yield two scores. These two scores were then correlated. This split-half reliability coefficient, which is significant, gives the correlation between the two halves of the scale and consequently refers to the reliability of the scale with one-half the number of items that the scale itself contains.

Another reliability coefficient of the scores on the scale was obtained from the split-half reliability coefficient. The SpearmanBrown reliability coefficient of a high significant .79 indicates the reliability of the scale in its entire length, that is, of scores based on all of the items.

Validity. Since the resolution scale was initially developed for this study, it was not tested for validity. However, the researcher did ask ten divorced people who ranged from non-professionals to health professionals to read the directions and items for clarity and pertinence. All ten readers found the directions to be clear and concise, and they found the items to be unambiguous and to be ascertaining relevant information. In fact, all ten said that most of the statements were very much related to their own divorce process.

This concludes the methodology for the study. The next chapter focuses on the results of the study. 


\section{CHAPTER I V \\ RESULTS OF THE STUDY}

In this chapter the tabulation of data will be presented which will include the characteristics of the sample and the collected data for each of the variables. In addition, the data will be analyzed to test the five hypotheses stated for the study.

\section{Tabulation of Data}

Characteristics of sample. One hundred seventy individuals participated in the study. Table 1 summarizes the characteristics of this sample. For a more detailed description of the characteristics of the sample, see Appendix B, pp. 125-127.

The subjects who participated in this study may not be representative of the divorce population of Hampshire County in Massachusetts. A variety of reasons caused certain people to participate in the study; yet, different reasons caused others not to participate. Since the sample contains only those persons who returned the completed questionnaires, the sample is not truly random and probably contains some distortion.

It was indicated to the researcher (by phone calls, letters, and written comments on the blank space provided on the questionnaires from 95 out of 170 individuals) that some of those who responded were 


\section{TABLE 1}

Characteristics of Sample

\begin{tabular}{|c|c|}
\hline CHARACTERISTICS & $\begin{array}{c}\text { ADJUSTED } \\
\text { PERCENTAGS }\end{array}$ \\
\hline $\begin{array}{l}\frac{\text { Sex }}{\text { Male }} \\
\text { Female }\end{array}$ & $\begin{array}{l}39 \\
61\end{array}$ \\
\hline $\begin{array}{l}\frac{\text { Age }}{20-29} \\
30-39 \\
40-59\end{array}$ & $\begin{array}{l}62 \\
34 \\
14\end{array}$ \\
\hline $\begin{array}{l}\text { Employed } \\
\text { Yes } \\
\text { No }\end{array}$ & $\begin{array}{l}70 \\
30\end{array}$ \\
\hline $\begin{array}{l}\frac{\text { Religious }}{\text { Yes }} \\
\text { No }\end{array}$ & $\begin{array}{l}40 \\
60\end{array}$ \\
\hline $\begin{array}{l}\text { Income } \\
0-9,999 \\
10,000-19,999 \\
20,000-29,999\end{array}$ & $\begin{array}{r}50 \\
44 \\
6\end{array}$ \\
\hline 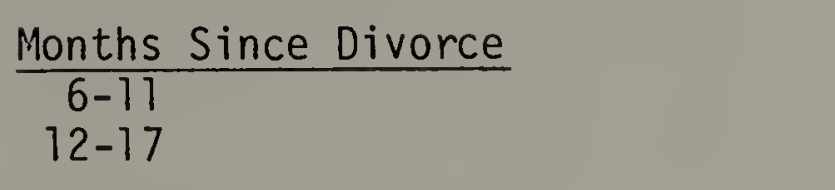 & $\begin{array}{l}47 \\
53\end{array}$ \\
\hline $\begin{array}{l}\text { Years Married } \\
1-6 \\
6-12 \\
13-32\end{array}$ & $\begin{array}{l}52 \\
31 \\
17\end{array}$ \\
\hline $\begin{array}{l}\text { Number of Children } \\
\text { None } \\
1-2 \\
3-8\end{array}$ & $\begin{array}{l}26 \\
50 \\
24\end{array}$ \\
\hline 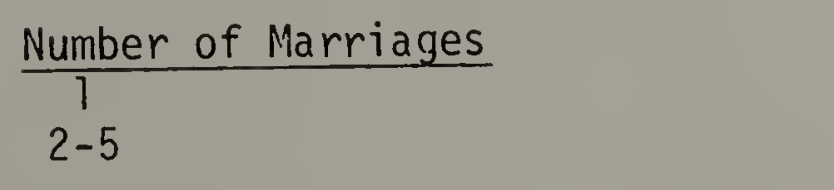 & $\begin{array}{l}78 \\
22\end{array}$ \\
\hline $\begin{array}{l}\frac{\text { Initiator of Divorce Proceedings }}{\text { Yes }} \\
\text { No }\end{array}$ & $\begin{array}{l}65 \\
35\end{array}$ \\
\hline $\begin{array}{l}\text { Have Intimate Relationship } \\
\text { Yes } \\
\text { No }\end{array}$ & $\begin{array}{l}70 \\
30\end{array}$ \\
\hline
\end{tabular}


TABLE 1--Continued

\begin{tabular}{lc}
\hline \hline CHARACTERISTICS & $\begin{array}{c}\text { ADJUSTED } \\
\text { PERCENTAGES }\end{array}$ \\
\hline Remarried Since Divorce & 4 \\
\hline Yes & 96 \\
No & \\
Feeling Worthy Toward Self & 26 \\
\hline Worthless to Below Average Worth & 74 \\
Above Average Worth to Great Worth & \\
Feeling Worthy Toward Ex-Spouse & 40 \\
Worthless to Below Average Worth & 60 \\
Above Average Worth to Great Worth & \\
Feeling Happy Toward Self & 27 \\
Very to Slightly Unhappy & 73 \\
Very to Slightly Happy & \\
\hline
\end{tabular}

NOTE: Additional characteristics concerning remarriage and feelings of worthiness and happiness were also collected. These additional characteristics, however, were not analyzed. 
hurt from the divorce experience and wanted to participate in the study as a way of exposing certain feelings and thoughts. Others viewed divorce as a painful experience but wanted to learn from it. A few seemed to be looking for help and some free advice. Others felt good about their divorce and themselves and wanted to participate in the study as a way of affirming themselves. Some appreciated the opportunity in giving information which they thought might be helpful to others who may also divorce.

It was also indicated to the researcher by a few individuals that they did not want to participate in the study because of the following reasons: opposed to questionnaire method of investigation, considered matters concerning marriage and divorce private and exclusive, angered and indignant about being part of a sample, and did not want to be reminded of a bad memory. Furthermore, it can be speculated that others may have experienced divorce as a negative event which was past and did not want to deal with it any longer. Others may have had no particular bad regrets about their divorce but viewed it as finished and over. Some may still have been undergoing a great deal of turmoil and stress and may not have been able to fill out the questionnaires.

Since there is no way of determining the motivations, attitudes and biases of those who self-selected to respond to the questionnaires, one must be careful in generalizing from the findings in this study.

Dependent and independent variables. The variables which were central to the study comprised the following: guilt; resolution of the divorce crisis; single attribution of responsibility to self, to ex-spouse, to 
external factors; and multiple attribution including ex-spouse and excluding ex-spouse.

Of the 170 individuals who participated in the study, 30 individuals did not completely fill out the questionnaires on guilt and/or resolution of the divorce. Therefore, the scores of the variables in Table 2 were tabulated from 140 subjects.

\section{TABLE 2}

Tabulation of Scores on Guilt and Resolution

\begin{tabular}{l|c|r|c}
\hline & RANGE OF SCORES & MEAN & STANDARD DEVIATION \\
\hline Guilt & 14 to 100 & 60.40 & 19.34 \\
Resolution & -15 to 42 & 8.33 & 11.81 \\
\hline
\end{tabular}

Single attributions made to self totaled 3 , made to ex-spouse totaled 27, and made to external factors totaled 12 .

The total attributions made to self regardless of whether they were single or multiple were 91 . The total attributions made to exspouse regardless of whether they were single or multiple were 133 . The total attributions made to external factors regardless of whether they were single or multiple were 105.

Multiple attributions including ex-spouse totaled 108 and excluding ex-spouse totaled 12.

For the raw data on guilt, resolution of the divorce crisis, and attributions of responsibility, see Appendix B, pp. 115-124. 
Analysis of Data

The data for each hypothesis was analyzed to evaluate its significance in order to determine whether or not the hypothesis was supported.

Hypothes is 1.

Guilt will be inversely related to the positive resolution of the divorce resolution.

Guilt scores and resolution scores of divorcees were collected. (For the data, see Appendix B, pp. 115-124.) The amount of variation of resolution scores explained by guilt scores was estimated using multiple regression analysis. See Table 3 for the summary table of the analyses for Hypothesis 1 and Hypothesis 2.

It was estimated that only .481 percent of the variance of resolution scores was accounted for by guilt scores. The $F$ ratio of .19 at the .672 level of significance indicates that this hypothesis was not supported. Guilt has no significant inverse relationship to the positive resolution of the divorce crisis.

\section{Hypothesis 2.}

Positive resolution will not be significantly related to any of the single attributions of responsibility: (a) to self,

(b) to ex-spouse, or (c) to external factors.

Single attribution of responsibility scores of divorcees were collected. (For the data, see Appendix B, pp. 115-124.) The amount of variation of resolution scores explained by a single attribution of responsibility was estimated using multiple regression analysis. See Table 3 for the summary table of the analyses for Hypotheses 1 and 2. 


\section{TABLE 3}

Summary of Multiple Regression Analysis for Dependent Variable (Divorce Resolution) and Independent Variables (Guilt, Single Attributions of Responsibility, and Combinations of Guilt and Single Attributions)

\begin{tabular}{c|c|c|c|c|c}
\hline \hline STEP & INDEPENDENT VARIABLE & F RATI0 & SIGNIFICANCE & R SQUARE & R SQUARE \\
CHANGE
\end{tabular}

NOTE: This is the summary table given at the end of the computer printout for multiple regression analysis. Each independent variable is given in a sequential listing which was determined by its respective contribution (greatest to least) in explaining the variance of the dependent variable, divorce resolution. "R Square" represents the cumulative percent of variance of resolution scores accounted for by each of the independent variables listed. The remaining percent which is not accounted for (i.e., the difference between the last R Square entered on the table and 100 percent) is that amount of variance of resolution scores accounted for by the countless other variables not identified and tested in this study. "R Square Change" represents the percent of variance of resolution scores accounted for by only that particular independent variable. "F Ratio" is the measurement of significance. The higher the $F$ ratio, the more likely the variance of resolution scores is due to that particular variable as opposed to being due to sample error. "Significance" indicates how many times out of a thousand the variance of resolution scores is accounted for by sample error (or chance) as opposed to being accounted for by that particular error. 
The single attribution of responsibility to self accounted for only .187 percent of the variance of resolution scores. The $F$ ratio of .06 at the .810 level of significance for single attribution to self indicates that "a" of the hypothesis was supported. The single attribution of responsibility made to self is not significantly related to the positive resolution of the divorce crisis.

The single attribution of responsibility made to ex-spouse accounted for 45 percent of the variance of resolution scores. The $F$ ratio of 16.44 at the .001 level of significance indicates that "b" of the hypothesis was not supported. The single attribution of responsibility made to ex-spouse is significantly related to the negative resolution of the divorce crisis.

The single attribution of responsibility to external factors accounted for only .213 percent of the variance of resolution scores. The $F$ ratio of .08 at the .784 level of significance for single attribution to external factors indicates that "c" of the hypothesis was supported. The single attribution of responsibility made to external factors is not significantly related to the positive resolution of the divorce crisis.

Additional variables were also analyzed. These comprised the combined interactions between guilt and each of the single attributions. The combination of the attribution to self with guilt accounted for only 9.15 percent of the variance of resolution scores. The $F$ ratio of 3.80 at the .066 level of significance indicates that this variable is not significantly related to the resolution of the divorce crisis. The combination of the attribution to ex-spouse with guilt ac- 
counted for only .095 percent of the variance of resolution scores. The $F$ ratio of .03 at the .859 level of significance indicates that this variable is not significantly related to the resolution of the divorce crisis.

The combination of the attribution to external factors with guilt does not appear on the summary table (Table 3 ) because its partial $F$ ratio was insufficient (too low). Therefore, further computation was stopped because the inclusion of that variable would provide no additional improvement on the computations done on the previous variables (Nie, Hu11, Jenkins, Steinbrenner \& Bent, 1975, p. 447). In other words, it would not improve the amount of variance which has already been accounted for by the preceding variables.

The variable, length of time from divorce, was also included because it served as a control in order to evaluate whether it confounded the other independent variables. However, it accounted for only 1.18 percent of the variance of resolution scores. The $F$ ratio of .48 at the .499 level of significance indicates that length of time from divorce has minimal effect on the independent variables.

Hypothes is 3.

Positive resolution will be significantly related to multiple attributions as opposed to single attribution.

Multiple attributions of responsibility scores were collected. (For raw data, see Appendix B, pp. 115-124.) The amount of variation of resolution scores explained by multiple attributions of responsibility was estimated using multiple regression analysis. See Table 4 for the summary table of the analysis. 
TABLE 4

Summary of Multiple Regression Analysis for Dependent Variable (Divorce Resolution) and Independent Variables (Multiple Attributions)

\begin{tabular}{c|c|c|c|c|c}
\hline \hline STEP & INDEPENDENT VARIABLE & F RATIO & SIGNIFICANCE & R SQUARE & $\begin{array}{c}\text { R SQUARE } \\
\text { CHANGE }\end{array}$ \\
\hline 1 & $\begin{array}{c}\text { Multiple attribution ex- } \\
\text { cluding ex-spouse }\end{array}$ & 6.68302 & .018 & .25046 & .25046 \\
2 & $\begin{array}{c}\text { Multiple attribution in- } \\
\text { cluding ex-spouse }\end{array}$ & .47581 & .499 & .26877 & .01831 \\
\hline & Length of time from divorce & .84260 & .371 & .30147 & .03270 \\
\hline
\end{tabular}

Of the various combinations of multiple attributions which can be made (i.e., ( 1 ) to self, to ex-spouse, and to external factors; (2) to self and ex-spouse; (3) to ex-spouse and to external factors; and (4) to self and to external factors), it was estimated that the one combination which was accounting for 25 percent of the variance of resolution scores was the multiple attribution excluding ex-spouse (i.e., to self and to external factors). The $F$ ratio of 6.68 at the .018 level of significance indicates that this hypothesis was supported. The multiple attribution of responsibility (excluding ex-spouse) is significantly related to the positive resolution of the divorce crisis as opposed to a single attribution which is not.

The multiple attributions of responsibility (including exspouse) accounted for 1.83 percent of the variance of resolution scores. The $F$ ratio of .47 at the .499 level of significance indicates that those attributions do not significantly relate to the positive resolution of the divorce crisis.

The variable, length of time from divorce, which was used as a 
control, was also analyzed. However, this variable accounted for only 3.27 percent of the variance of resolution scores. The $F$ ratio of .84 at the .371 level of significance indicates that the length of time from divorce does not confound the other independent variables to any significant degree.

\section{Hypothes is 4.}

There is no significant relationship between the characteristics:
(a) income;
(b) feeling religious;
(c) having an intimate relationship;
(d) age;
(f) number of children;
(e) sex;
(g) number of years married;
(h) number of marriages;
(i) employment;
(j) initiator of divorce proceedings;
and guilt.

Characteristics of the subjects were collected. (For the data, see Appendix B, pp. 125-127.) The amount of variation of guilt scores explained by characteristics was estimated using multiple regression analysis. See Table 5 for the summary table of the analysis.

Of all the data on characteristics collected, it was estimated that the combined variables of feeling religious and initiating the divorce proceedings were accounting for 41 percent of the variance of guilt. The $F$ ratio of 6.64 at the .007 level of significance indicates that "b" and " $j$ " of the hypothesis were not supported. There is a significant relationship between two of the combined characteristics (feeling religious and initiator of the divorce proceedings) and guilt.

The remaining characteristics (income, having an intimate relationship, number of children, number of years married, and sex) account for too little of the variance of guilt scores. Thus, there is no significant relationship between the remaining characteristics and 


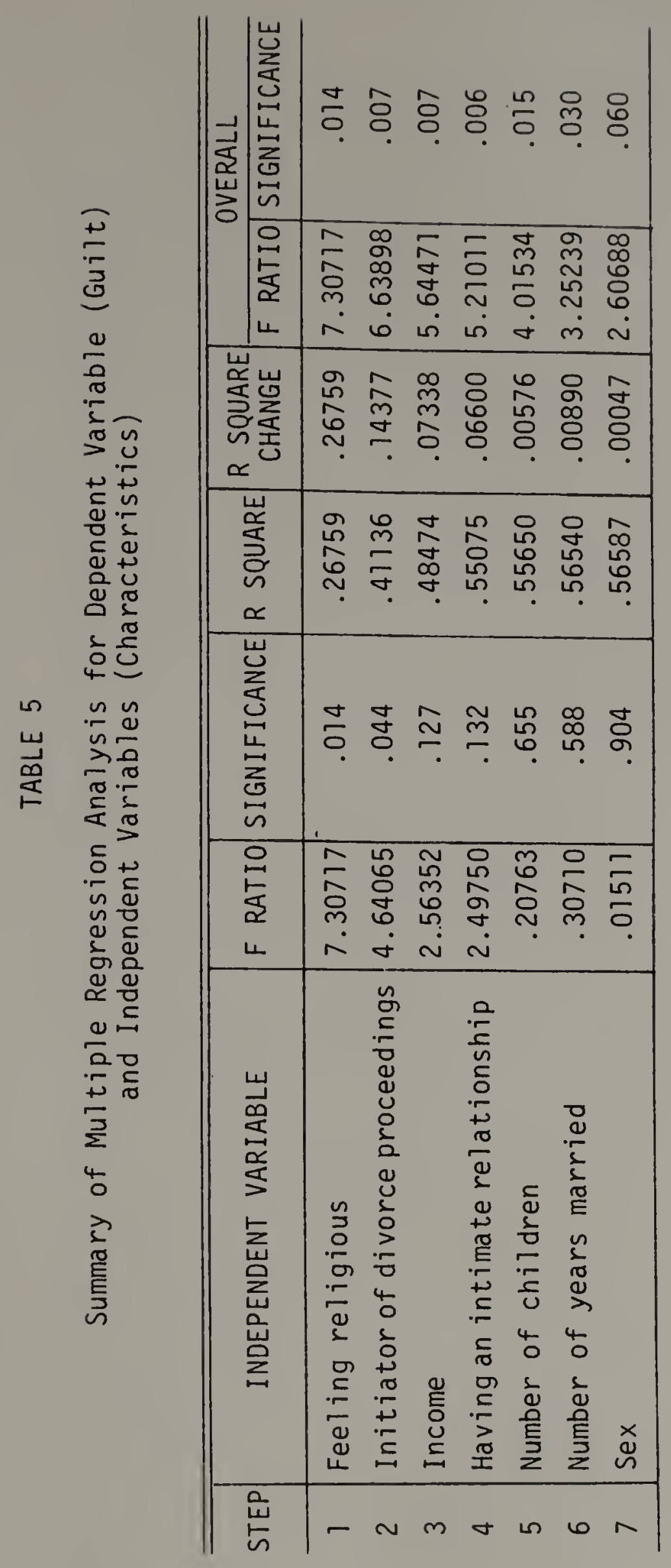


guilt.

The characteristics (age, number of marriages, and employment) do not appear on the summary table because their partial $F$ ratios were insufficient for further computation.

In addition, length of time from divorce, which was used as a control, does not appear on the summary table, because its partial $F$ ratio was insufficient for further computation.

\section{Hypothes is 5 .}

There is no significant relationship between the characteristics:

(a) income;

(b) feeling religious;

(c) having an intimate relationship;

(d) age;

(e) sex; and the positive resolution of the divorce crisis.

(f) number of children

(g) number of years married;

(h) number of marriages;

(i) employment;

(j) initiator of divorce

The amount of variation of resolution scores explained by characteristics was estimated using multiple regression analysis. See Table 6 for the summary table of the analysis.

Of all the data on characteristics collected, it was estimated that the combined variables of initiating the divorce proceedings and having an intimate relationship were accounting for 46 percent of the variance of resolution scores. The $F$ ratio of 7.94 at the .003 level of significance indicates that " $j$ " and " $c$ " of the hypothesis were not supported. There is a significant relationship between two of the combined characteristics (initiator of the divorce proceedings and having an intimate relationship) and a positive resolution of the divorce crisis.

The remaining characteristics (number of marriages, feeling re- 


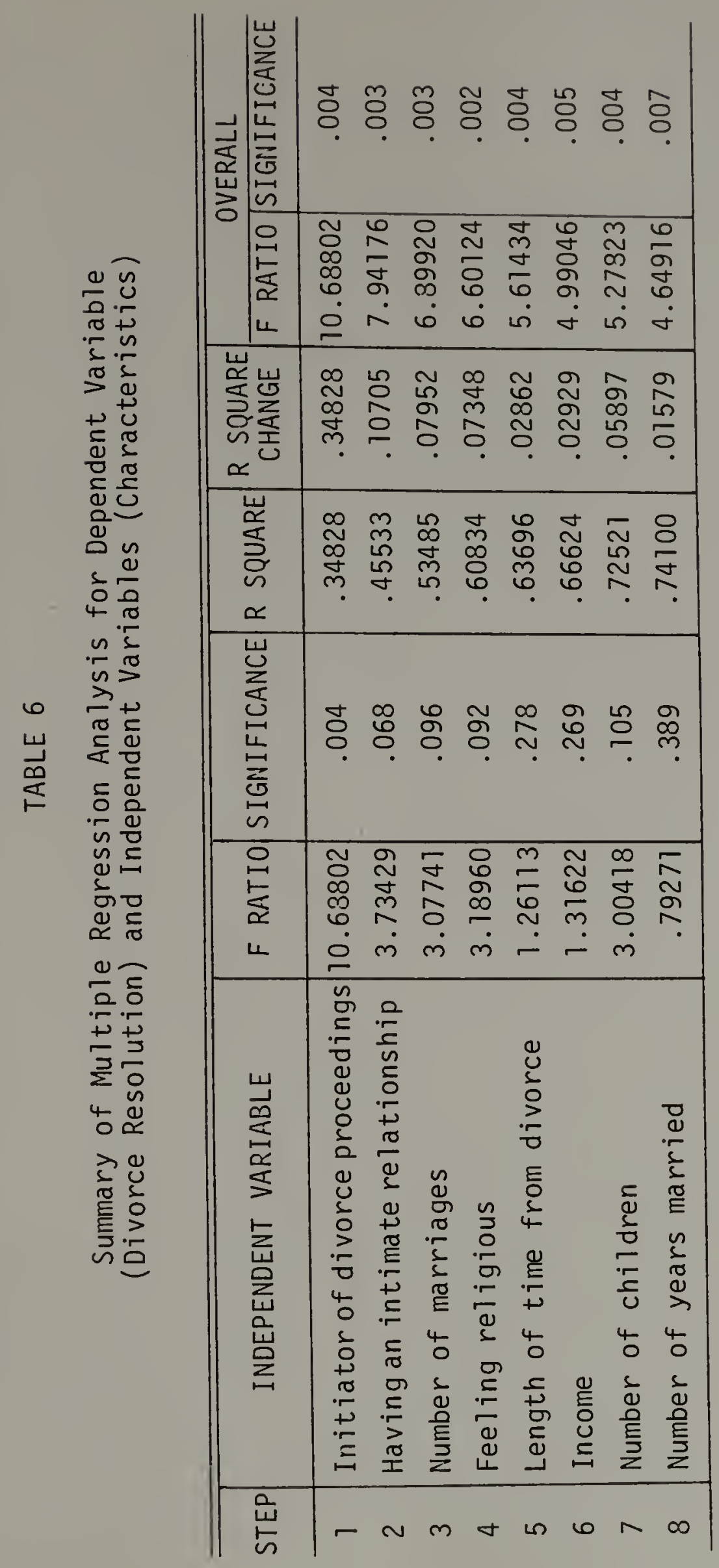


ligious, income, number of children, and number of years married) account for too little of the variance of resolution scores. Thus, there is no significant relationship between these demographics and the positive resolution of the divorce crisis.

Length of time from divorce, which was used a control, also accounts for too little of the variance of resolution scores. Therefore, it does not confound the independent variables to any significant degree.

The characteristics (age, sex, and employment) do not appear on the summary table because their partial $F$ ratios were insufficient for further computation.

This concludes tabulating the data for each of the variables and analyzing the data for each of the hypotheses. The next chapter explores more fully the results obtained from the analysis of data. 


\section{HAPTER V \\ DISCUSSION OF FINDINGS}

The purpose of this study was to explore what effects the interactions between guilt and the attribution of responsibility to self, to ex-spouse, and to external factors have on the resolution of the divorce crisis. The results of the analysis of data are discussed in this chapter. An examination of these results from each of the hypotheses reveals their meaning and their connection with the related literature.

\section{Hypothes is 1.}

Guilt will be inversely related to the positive resolution of the divorce crisis.

Data on guilt and resolution of the divorce crisis among divorcees were collected. (For raw data, see Appendix B, pp. 115-124.) An analysis of the data indicated that the amount of generalized chronic guilt a divorcee experienced had no significant relationship to the level (positive or negative) of resolution of the divorce crisis (see Table 3, p. 60).

This finding may indicate that guilt does not affect, to a significant degree, how one resolves one's divorce crisis. However, it is also possible that this study did not test adequately the amount of guilt of the individuals in order to ascertain if guilt, in fact, was related to the resolution of the divorce crisis. 
The Mosher Guilt Inventory (see Appendix A, pp. 110-113), which was used in this study, was developed from examining the guilt responses of college students. Reliability and validity studies of the inventory were also conducted on college students. It is questionable, therefore, that the Mosher Guilt Inventory would be applicable to measuring guilt in the sample of this study which comprised a population of 20 to 59 year olds. In addition, the inventory was developed in the 1960 s and the most recent validity study on public record was conducted in the early 1970s. The test items might, therefore, be antiquated. Consequently, guilt may not have been measured accurately in this study which would mean that this hypothesis may not have been adequately tested.

The following two hypotheses are combined for the purpose of discussion.

Hypothes is 2.

Positive resolution will not be significantly related to any of the single attributions of responsibility: (a) to self, (b) to ex-spouse, or (c) to external factors.

\section{Hypothes is 3.}

Positive resolution will be significantly related to multiple attributions as opposed to single attribution.

Data on single and multiple attributions of responsibility among divorcees were collected. (For raw data, see Appendix B, pp. 115 124.) An analysis of the data on single attribution indicated that the attribution of responsibility to ex-spouse was significantly related to the negative resolution of the divorce crisis (see Table 3, p. 60). An 
analysis of the data on multiple attribution indicated that multiple attributions in which ex-spouse was excluded (i.e., multiple attribution to self and to external factors) were significantly related to a positive resolution of the divorce crisis as opposed to single attribution (see Table 4, p. 63).

These findings supported the connection between attribution theory and crisis theory. The attribution theory literature suggests it is unlikely that one thing or one person is responsible for causing a particular event (Allport [Buckley], 1968, p. 345; Kelley [Jones et al.], 1972, p. 1; Watzlawick et a1., 1967, p. 127) and that more cognitive effort is needed in seeking further and possibly better explanations for causing a particular event (Kanouse [Jones et al.], 1972, p. 131).

Furthermore, crisis theory literature suggests that problemsolving abilities and having a reality perspective are needed in order for individuals to positively resolve a crisis (Caplan, 1964, pp. 53-54; Rapoport [Parad], 1972, pp. 26-29).

Therefore, as attribution theory and crisis theory would suggest, it was found in this study that the individual who makes multiple attributions (to self and to external factors) for the marriage terminating is more apt to expend greater cognitive effort to seek more accurate explanations and this realistic perspective enhances the individual's problem-solving abilities. Consequently, this enables the individual to achieve a more positive resolution of the divorce crisis.

Conversely, the individual who only attributes the ex-spouse for the marriage terminating may not be as objective in examining the whole situation. This suggests less of a reality perspective and less 
problem-solving ability. Therefore, the individual who makes the attribution of responsibility to ex-spouse is more apt to have resolved the divorce crisis negatively.

Similar results were obtained in a study by Bulman and Wortman (1976). Data on the attribution of responsibility and the level of resolution following a crisis (an accident which left the victim severely paralyzed) were analyzed. They found that the accident victims who attributed the other person as being responsible for causing the accident resolved the crisis negatively. In the same study, however, the victims who attributed themselves as being responsible for causing the accident resolved the crisis positively.

Both these findings from the Bulman and Wortman study have connotations similar to the findings in this study. The attribution of responsibility to self connotes an acknowledgment of one's own agency: a capability of responding in one's own behalf. The individual genuinely feels responsible which enables the individual to act and respond thereby having the potential to positively resolve an unpleasant crisis.

On the contrary, the attribution of responsibility to ex-spouse (or "to the other" as in the Bulman and Wortman study) connotes a denial of one's own agency: an inability to respond in one's own behalf. The individual might feel helpless and victimized so that the individual is not apt to respond in order to remedy the unpleasant crisis.

Since the findings from Hypothesis 2 and Hypothesis 3 lend credence to the contention that particular attributions of responsibility for a marriage terminating can be linked with various levels of resolution of a divorce crisis, it can be an aid for those in the helping pro- 
fessions to know the attributions of responsibility the divorcees are making. Encouraging the divorcees to look objectively and consider their own shortcomings and other factors (beyond their ex-spouse) for their marriage terminating, can serve as an opportunity for them to grow from the divorce experience thereby resolving the crisis positive1y. Moreover, for those divorcees who attribute the responsibility of the marriage terminating to themselves, the counselor or therapist would do well in supporting them through that feeling and help them utilize that acknowledgment of their own agency to grow further.

It has been demonstrated in a detailed case study presented by Skilbeck (1974) that attributions of responsibility can play a crucial role in the resolution of a crisis. In helping a client who was in a situational crisis look more objectively at the crisis and re-attribute the cause to more appropriate causes, he found that the counselor or therapist has an important role in guiding the client to consider all causal factors thereby helping to resolve a crisis positively.

However, it must be pointed out that the therapist or counselor be cautious in thinking that the divorcee who attributes the responsibility to particular causes is really feeling that way. It could be that the individual makes certain attributions merely because of the therapist's guidance or instructions. It seems that for the crisis to resolve positively, the individual should genuinely feel the responsibility.

In addition, these findings from Hypothesis 2 and Hypothesis 3 which 1 ink particular attributions of responsibility with various levels of divorce resolution, suggest the possible need to look more 
critically at the legal system. Since most divorces are granted through the ruling based on fault, attributing responsibility to the other spouse for the marriage terminating is usually necessary to receive a divorce and sometimes encouraged by the legal representative in order to obtain a better settlement when such testimony is presented to the judge presiding over the court hearing. Therefore, the very nature of divorce proceedings encourages the individual to attribute responsibility to the other spouse which might limit examining one's own shortcomings, might foster feeling helpless and victimized, might deny one's sense of agency, and might generate bitterness and hostility. Thus, the individual might not be able to respond and move forward in a constructive manner to resolve the divorce crisis positively.

The Iiterature (Goldstein \& Gitter, 1970, pp. 12-15; Cantor, 1970, pp. 10-12) supports the view that the legal system, through its concept of fault for procuring a divorce, can have a negative effect on the divorce resolution since post divorce relations between spouses and between spouses and children can be harmed. They have pointed out that the fault concept and the adversary system cause incalculable damages on divorcing spouses and their children due to the resulting hatred, bitterness, and resentment.

Several respondents in this study volunteered additional information pertaining to the legal system. (They wrote on the blank space which was provided on the questionnaire for comments about their particular experience with divorce.) Their comments addressed some of the problems they encountered with their spouses and children due to the divorce procedure in the courts and with the lawyers. 
Breakthroughs in reforming the divorce procedure have been slowly evolving. "No-fault" divorce, instituted in many states, eliminates the necessity of placing blame on the spouse. Perhaps legislators should institute "no-fault" divorce in all the states and lawyers should encourage their clients, when possible, to use the "no-fault" grounds.

\section{Hypothes is 4.}

There is no significant relationship between the characteristics (income, feeling religious, having an intimate relationship, age, sex, number of children, number of years married, number of marriages, employment, and initiator of divorce proceedings) and guilt.

Characteristics of the subjects were collected. (For the data, see Appendix B, pp. 125-127.) An analysis of the data indicated that the amount of generalized chronic guilt a divorcee experienced had no significant relationship to the characteristics with the exception of feeling religious and initiating the divorce proceeding (see Table 5, p. 65).

This finding indicates that divorcees who feel religious and initiate the divorce proceeding tend to have a high amount of guilt as measured on the Mosher Guilt Inventory. However, the value of this finding is questionable since guilt may not have been measured accurately in this study. Thus, this hypothesis may not have been adequately tested.

\section{Hypothes is 5.}

There is no significant relationship between the characteristics (income, feeling religious, having an intimate relationship, age, sex, number of children, number of years married, number of marriages, employment, and initiator of divorce proceedings) and the positive resolution of the divorce crisis. 
An analysis of the data indicated that the positive resolution of the divorce crisis had a significant relationship with the characteristics of being the initiator of the divorce proceedings and having an intimate relationship (see Table 6, p. 67).

This finding supports the literature which suggests that people who resume maintaining physiological and psychological needs following a crisis are in a state of positive resolution (Rapoport [Parad], 1972, p. 28). Divorcees who initiated divorce proceedings had taken action to meet certain needs which were not being met in an unsatisfying marriage. Also, divorcees who have an intimate relationship following a divorce are taking action to satisfy certain needs. It would follow, then, that these divorcees who initiated divorce proceedings and have an intimate relationship have a sense of agency and are able to take action in resolving their crisis positively.

Similar results concerning intimate relationships were found in a longitudinal study on divorce. Hetherington et al. (1976) found that the divorcee who had an intimate relationship was positively resolving the divorce crisis as opposed to one who was not. Also, Putney (1975), in his case studies of separated and divorced people, found that maintenance and/or development of "supportive relationships" were core factors in positively resolving the crisis of separation and divorce. He included an intimate relationship as being one of several others which comprised "supportive relationships."

Further analysis indicated that the remaining characteristics (income, feeling religious, age, sex, number of children, number of years married, number of marriages, and employment) had no significant 
relationship to the level of divorce resolution. This finding differed from those found in a related study by Blair (1969, p. 68) who investigated how well women were adjusting to their divorce. She found that older women and those married longer had greater difficulty in adjusting to their divorce than younger women and those married for a shorter length of time. Even though Blair's study only tests the adjustment of women, some clinical studies (Fisher, 1974, p. 97; Weiss, 1975, pp. 234-253) claimed that older men and women and those married longer also tended to have more difficulty adjusting to the divorce. In addition, the study on the aftermath of divorce conducted by Hetherington et al. (1976, pp. 11-12) found that divorced parents who were older and who had been married longest had the greatest negative change in self concept. Although this finding did not test specifically how these characteristics correlated with divorce resolution, a negative self concept may influence a person's coping ability.

The possible reason this study did not show any significant relationship between divorce resolution and the characteristics of age and number of years married is that most of the subjects from which the data were collected were young (52 percent between 20 and 29) and married a relatively short time (52 percent between one and six years). Perhaps different findings would be revealed in a study in which the random sample was stratified according to these variables.

The finding in this study which related to income differed with those from other studies (Blair, 1969, p. 69; Goode, 1956, pp. 183-195; Waller, 1967, p. xx) which found that low income levels were related to negative divorce resolution. The discrepancy between the findings 
in this study and those in the others could be due to the fact that the other studies were done from ten to twenty-five years ago when there were fewer social agencies and less public monies for low income individuals. Now, low income individuals have a greater use of social agencies and have a greater availability of public monies. Consequently, low income may no longer be as severe a hardship as it once was in having such a negative effect on divorce resolution.

The one variable, length of time from divorce, was analyzed for each of the five hypotheses. It served as a control in order to evaluate its effect on the other independent variables. However, for each of the hypotheses tested, its analysis indicated that length of time from divorce had minimal effect on the independent variables which further indicated that it had minimal effect on the resolution of divorce crisis. In the Blair study (1969, p. 70), it was found that the shorter length of time one was divorced, the more difficult was the adjustment to the divorce. However, the length of time divorced ranged from less than five to thirty-five years. In this study, the length of time divorced ranged from six to seventeen months. Perhaps this is not a long enough range to reveal any significant relationship with resolution of divorce. Besides short time range, another possibility length of time from divorce did not reveal any significant relationship with divorce resolution might be due to some distortion in the sample.

In concluding this chapter, all the findings support some of the principles which underlie Caplan's theory: the components necessary for a positive outcome in resolving a crisis include the interplay between favorable internal forces (problem-solving ability, reality perspective, 
taking action) and favorable external forces (meaningful relationships with others). Making multiple attributions which included oneself and external factors suggest greater problem-solving ability, better perspective of reality, and greater sense of one's own agency. In addition, initiating the divorce proceedings and attaining intimacy with another also suggests greater sense of one's agency. Moreover, attaining intimacy with another suggests the ability to have meaningful relationships.

Furthermore, the very nature of crisis provides a time ripe for new learning and growth. With divorce, it presents an opportunity for the individual to examine and take ownership of any shortcomings and to understand how these shortcomings and other factors affected the marital relationship. Learning about the mistakes of the past helps the individual to move onward and achieve satisfaction in continued living.

Making attributions to the ex-spouse, on the other hand, suggests not examining one's own part and possibly feeling helpless in not assuming any responsibility. Moreover, even if the ex-spouse were largely responsible, attributing responsibility to the ex-spouse may be suggestive of continuing to harbor bitter and hostile thoughts about that. Also, the individual may not be able to free her/himself from that situation and focus on moving forward.

Therefore, for any crisis to be a growthful experience, the individual needs to be understanding and accepting of oneself, not dwe 11 on the mistakes of the past no matter who was responsible, and free oneself in order to reduce feelings of bitterness and helplessness. 
The next chapter deals with summarizing the study and presenting the conclusions and implications. 


\section{HAPTER VI \\ SUMMARY, CONCLUSIONS, AND IMPLICATIONS}

This chapter summarizes the study, presents the conclusions derived from the findings of the study, and discusses the implications of the study which include recommended future studies to be conducted and limitations of this study.

\section{Summary}

The purpose of this study was to examine the variables of guilt and attribution of responsibility in individuals who are resolving their divorce crisis. Guilt reactions and attributing responsibility to their ex-spouse for their marriage terminating, have been reported as frequent phenomena experienced by divorcees (Fisher, 1968, pp. 29-30; Hetherington et al., 1976, p. 13; Kessler, 1975, p. 107; Steinzor, 1969, pp. 2223; Weiss, 1975, pp. 14-24).

According to the literature, experiencing guilt may immobilize one to such an extent that constructive action is 1 imited in resolving a crisis positively. Assuming that divorce is a crisis, it would follow that those individuals with high guilt scores would tend to negatively resolve their divorce crisis more than those individuals with low guilt scores.

According to the literature, making multiple attributions for the occurrence of a particular event connotes a greater sense of reality 
and better problem-solving ability than making a single attribution. Assuming that a greater sense of reality and better problem-solving ability are important contributions for positively resolving a crisis, it would follow that those individuals making multiple attributions for their marriage terminating would tend to positively resolve their divorce crisis more than those individuals making a single attribution.

The sample consisted of 170 men and women, between the ages of 20 and 59, who had been granted a divorce from the Hampshire County Court of Massachusetts from 6 to 17 months prior to the investigation. The researcher sent an initial letter of explanation followed by questionnaires requesting relevant information examining the variables being tested. The entire data collection was done through the mail.

Guilt was measured by the Mosher Guilt Inventory, the resolution of the divorce crisis was measured by the researcher's resolution scale, and attributions of responsibility were tabulated from responses on the personal data questionnaire. Demographic and other information was also obtained from the personal data questionnaire.

It was hypothesized that guilt would be inversely related to the positive resolution of the divorce crisis, but that multiple attributions of responsibility would be directly related to the positive resolution of the divorce crisis. Also, it was hypothesized that there would be no significant relationship between positive resolution of the divorce crisis and single attribution of responsibility. Further, it was hypothesized that there would be no significant relationship between various characteristics and each of the two variables: guilt and positive resolution. 
The data were subjected to statistical analysis. Multiple regression analysis was used to test the relationship between each dependent variable and each set of independent variables. For each hypothesis that was being tested, an $F$ ratio was evaluated at the .05 level of significance.

The findings were as follows:

1. Hypothesis 1 was not supported.

Guilt had no significant inverse relationship to the positive resolution of the divorce crisis.

2. Hypothesis 2 was supported only for single attributions made to self and to external factors.

a. Single attribution of responsibility made to self was not significantly related to the positive resolution of the divorce crisis.

b. Single attribution of responsibility made to ex-spouse was significantly related to the negative resolution of the divorce crisis.

c. Single attribution of responsibility made to external factors was not significantly related to the positive resolution of the divorce crisis.

3. Hypothesis 3 was supported only for multiple attributions excluding ex-spouse.

a. Multiple attributions excluding ex-spouse were significantly related to the positive resolution of the divorce crisis.

b. Multiple attributions including ex-spouse were not significantly related to the positive resolution of the divorce crisis.

4. Hypothesis 4 was supported only for characteristics including income, having an intimate relationship, age, sex, number of children, 
number of years married, number of marriages, and employment.

a. The characteristics including income, having an intimate relationship, age, sex, number of children, number of years married, number of marriages, and employment were not significantly related to guilt.

b. The characteristics including both feeling religious and initiating the divorce proceedings were significantly related to guilt. 5. Hypothesis 5 was supported only for characteristics including income, feeling religious, age, sex, number of children, number of years married, number of marriages, and employment.

a. The characteristics including income, feeling religious, age, sex, number of children, number of years married, number of marriages, and employment were not significantly related to the positive resolution of the divorce crisis.

b. The characteristics including both initiating the divorce proceeding and having an intimate relationship were significantly related to the positive resolution of the divorce crisis.

\section{Conclusions}

Based on the findings of this investigation for the sample studied, the following conclusions are made:

1. The chronic disposition of guilt of divorcees tended to have no effect on the resolution of the divorce crisis.

2. Divorcees who made a single attribution of responsibility to their ex-spouse as cause for their marriage terminating tended to resolve their divorce crisis negatively compared to divorcees who made a 
single attribution of responsibility to either themselves or to external factors.

3. Divorcees who made multiple attributions of responsibility to themselves and to external factors as causes for their marriage terminating tended to resolve their divorce crisis positively compared to divorcees who made multiple attributions of responsibility which included their ex-spouses.

4. Divorcees who indicated they were religious and those who initiated the divorce proceedings tended to experience more guilt than the other divorcees.

5. Guilt reactions tended not to be affected by divorcees' income, age, sex, number of children, number of years married, number of marriages, nor employment.

6. Divorcees who initiated the divorce proceedings and those who had an intimate relationship since their divorce tended to resolve their divorce crisis positively compared to the other divorcees.

7. Resolution of the divorce crisis tended not to be affected by divorcees' income, feeling religious, age, sex, number of children, number of years married, number of marriages, nor employment.

\section{Implications}

One purpose of the study was to increase the knowledge needed to predict, prevent, and treat the negative resolution of the divorce crisis. It was found that divorcees who made a single attribution of responsibility to their ex-spouse as cause for their marriage terminating tended to resolve their divorce crisis negatively. This finding 
suggests that single attribution to ex-spouse is an indicator of negative resolution of the divorce crisis. Moreover, it suggests these divorcees who place the responsibility on the other are possibly not examining their own shortcomings nor external factors which may have contributed to their marriage terminating. Consequently, in placing the responsibility on the other, they decrease the opportunity for their own growth in fully learning from the experience. Therefore, by identifying divorcees who make a single attribution of responsibility to their exspouse as cause for their marriage terminating, possible intervention can be implemented in order to alter the negative resolution. The intervention may need to take the form of helping those individuals take ownership for their part in causing the marriage to terminate thereby increasing their sense of responsibility. Other issues might need to be addressed as well. For instance, if not feeling any sense of responsibility or feeling helpless are issues over which individuals are struggling, then the therapy may need to help them gain a sense of their own efficacy.

The finding that divorcees who made multiple attributions of responsibility to themselves and to external factors as cause for their marriage terminating tended to resolve their divorce crisis positively, suggests that negative resolution can possibly be prevented. Moreover, it suggests these divorcees can examine their own shortcomings and take responsibility in changing, as necessary, thereby enriching themselves and growing from the experience. This enrichment and growth might even help them with future relationships. Therefore, by encouraging divorcees to examine all possible causes for their marriage terminating, 
negative resolution may be prevented. In addition, therapists should be supportive of those individuals who attribute part of the responsibility to themselves since those individuals are acknowledging their own agency. Through this support, then, individuals would experience reinforcement of their power and self-affirmation which would give them further impetus in their growing and learning from the divorce experience.

A study designed to determine the relationship between attributions of responsibility and the level of crisis resolution at different time periods during the separation and divorce phase would generate further knowledge and more conclusive data about predicting and preventing the negative resolution of the divorce crisis. Another similar longitudinal study could also be designed to examine the introduction of intervening variables (e.g., counseling or psychotherapy aimed at reattribution) to determine their effect on resolution.

In addition, these findings which link particular attributions of responsibility with various levels of resolution have implications for the legal system. Perhaps lawyers would be helpful to their clients if they did not encourage them to distort or exaggerate the process of attributing blame to their spouse in establishing grounds for a divorce. Moreover, by the very nature of being granted a divorce through the ruling based on fault, getting divorced confirms the process of attributing responsibility to the ex-spouse. Consequently, fostering "no-fault" as grounds for divorce might be of better service to people in their resolving the divorce experience more positively. A study focusing on attribution of responsibility and resolution of a "no-fault" 
divorce might yield interesting results.

Another finding from this study which possibly adds to the knowledge needed to predict and prevent the occurrence of negative resolution is that divorcees who both initiated the divorce proceedings and had an intimate relationship since their divorce tended to resolve their divorce crisis positively. An implication of this finding is that initiating the divorce proceedings may be predictive of a positive divorce resolution. If individuals are having difficulty in their marriage and they cannot reconcile their differences, then those individuals who initiate divorce proceedings may resolve the divorce crisis positively compared to those individuals who do not initiate the proceedings. The possible explanation for this is that if the initiator of the proceedings is genuinely acting in one's own behalf, then that person may have the potential to resolve the crisis better since they would be more ripe for learning and growing in the therapeutic process. In order to test this implication, an extension of this present study could have been done. The data from both ex-spouses who were married to each other would have had to have been compared.

One aspect of this study has specific implications for future research on guilt. This researcher used the Mosher Guilt Inventory, which was developed from examining the guilt responses of college students in the mid 1960s, because there were no other standardized tools to measure the chronic personality disposition of guilt. Since the subjects in this study ranged in age from 20 to 59 and since the Mosher Guilt Inventory is twelve years old, it is questionable whether guilt was measured appropriately in this study. Therefore, research is 
needed to measure guilt more adequately. In addition, perhaps more thought and research is needed to understand the whole concept of guilt. Together, this might yield more insight into the ramifications of guilt in human interactions. For instance, in relation to this study, such research might be able to assess the part, if any, guilt (projected guilt) had in attributing the responsibility to the ex-spouse.

This researcher did not test the resolution scale used in this study for validity due to the fact that the scale was only initially developed for this study. Therefore, further research is needed on the resolution of the divorce crisis to test the scale for validity.

Another purpose of this study was to collect and analyze previously unavailable data on attribution of responsibility. The aforementioned findings on attribution of responsibility and resolution of the divorce crisis adds to the further development of attribution theory. An extention of this present study would provide more knowledge on attribution of responsibility if the data from both ex-spouses who were married to each other were compared. Further development of the knowledge of attribution of responsibility could be generated with additional studies designed to examine attribution of responsibility during other 1 ife crises.

A major limitation of this study is the sample, which may be viewed as distorted, since it contains only those persons who, for whatever reason, wanted to participate in the study. Therefore, caution must be exercised in transposing the results to the general population of divorcees since the sample, from which the results were obtained, may not be truly representative of the divorce population. 
Another limitation of this study is the resolution scale. Twenty-six persons, out of the 170 who participated in the study, left out information on most of the items on the scale; consequently, they had to be deleted from the sample. This suggests there might have been some problem with the scale itself or the self-report method in collecting data.

Possibly those 26 individuals had difficulty in answering all the information which was requested of them for each item. Perhaps they could not remember how they felt or behaved prior to the divorce, or they might not have been able to assess their present feelings or behaviors. Even those who did answer the scale in its entirety might have had some difficulty with their responses, too, which might raise some concern about the accuracy of their resolution scores.

Therefore, a future study with another method or multiple methods of collecting data on the resolution of the divorce crisis might yield more and better results. Through the interview method, for instance, both verbal communication (content of the responses) and nonverbal communication (tone of voice, cadence of words, body language, etc.) would be analyzed as well.

In conclusion, a major contribution generated by the findings of this study is that the ability to respond and take action in one's own behalf is related to positively resolving the divorce crisis. Making multiple attribution which excluded ex-spouse, initiating the divorce proceedings, and having an intimate relationship reflect this unifying theme of putting into action one's sense of agency. Future studies directed at ascertaining other ways one puts into action one's sense 
of agency and correlating them with resolving other crises might be fruitful to investigate. If it is found that people who take action resolve more positively their crises, then additional studies can focus on the question of causality: does the change in attitude about oneself precede the ability to take action or is it a result of taking action that one feels better about oneself and can then resolve a crisis positively. 


\section{REFERENCES}

Abrams, R., \& Finesinger, J. Guilt reactions in patients with cancer. Cancer, $1953, \underline{6}(3), 474-482$.

Ackerman, N. Divorce and al ienation in modern society. Mental Hygiene, $1969, \underline{53}(1), 118-126$.

Allport, G. The open system in personality theory. In W. Buckley (Ed.), Modern systems research for the behavioral scientist. Chicago: Aldine Publishing Co., 1968.

Arieti, S. The intrapsychic self. New York: Basic Books, Inc., 1967.

Barnhi11, D. Divorce: Must one be a lonely number. Menninger Perspective, $1975, \underline{6}(2), 4-9$.

Benedek, E. Child custody laws: Their psychiatric implications. American Journal of Psychiatry, 1972, 129, 326-328.

Bernard, J. Remarriage. New York: Dryden Press, 1956.

Bernstein, M., \& Robey, J. The detection and management of pediatric difficulties created by divorce. Pediatrics, 1962, 30, 950-956.

Bertalanffy, L. von. General system theory. New York: Random House, 1964 .

Blacker, C.P. Disruption of marriage: Some possibilities of source. Lancet, 1958, I, 578-581.

Blair, M. Divorcees adjustment and attitudinal changes about life. Unpubl ished Doctoral Dissertation, The Florida State University, 1969.

Bluementhal, M. Mental health among the divorced. Archives of General Psychiatry, 1967, 16, 603-608.

Bohannon, P. Divorce and after. New York: Doubleday \& Co., 1970.

Bowlby, J. Separation anxiety: A critical review of the literature. Journal of Child Psychology and Psychiatry, 1961, 1, 251-269.

Branden, N. The psychology of self-esteem. New York: Bantam Books, 1969. 
Brenner, C. An elementary textbook of psychoanalysis. New York: Doubleday \& Co., Inc., 1957.

Briscoe, W., \& Smith, J. Depression in bereavement and divorce. Archives of General Psychiatry, 1975, 32, 439-443.

Briscoe, W.; Smith, J.; Robbins, E.; Marten, S.; \& Gaskin, F. Divorce and psychiatric disease. Archives of General Psychiatry, 1973, 29, $119-125$.

Brockway, N. Views on divorce. Unpublished manuscript, Yale University Law School, 1973.

Buchinal, L. Characteristics of adolescents from unbroken, broken and reconstructed families. Journal of Marriage and Family, 1964, $\underline{26}, 44-51$.

Bulman, R., \& Wortman, C. Attributions of blame and coping in the real world: Severe accident victims react to their lot. Unpublished manuscript, Northwestern University, 1976.

Burn, G. The child of divorce in Denmark. Bulletin of the Menninger Clinic, 1964,28 .

Cantor, D. A matter of right. The Humanist, 1970, 30(3), 10-12.

Caplan, G. Principles of preventive psychiatry. New York: Basic Books, Inc., 1964.

Carter, H., \& Glick, P. Marriage and divorce: A social and economic study. Cambridge, Massachusetts: Harvard University Press, 1970.

Chodoff, P.; Friedman, S.; \& Hamburg, D. Stress, defenses and coping behavior: Observations in parents of children with malignant diseases. American Journal of Psychiatry, 1964, 120(8), 743-749.

Cooper, D. The death of the family. New York: Random House, 1970.

Davis, W., \& Davis, E. Internal-external control and attribution of responsibility for success and failure. Journal of Personality, $1972, \underline{40}(1), 123-135$.

Davison, G. Differential relaxation and cognitive restructing in therapy with a paranoid schizophrenic or paranoid state. Proceedings of American Psychological Association, 1966, 177178.

Diekelman, N., \& Galloway, K. The middle years: A time of change. American Journal of Nursing, 1975, 994-996. 
Dies, R. Need for social approval and blame assignment. Journal of Consulting and Clinical Psychology, 1970, 35(3), 311-316.

Donavan, J.; Dressier, D.; \& Geller, R. Psychiatric crisis. The Journal of Nervous and Mental Disease, 1975, 161(3), 172-179.

Drake, R., \& Price, J. Depression: Adaptation to disruption and loss. Perspectives in Psychiatric Care, 1975, 13(4), 163-169.

Enge 1, G. A life setting conducive to illness: The giving-up/given-in complex. Annals of Internal Medicine, 1968, 69, 293-300.

Feldberg, R., \& Kohen, J. Family life in an anti-family setting: A critique of marriage and divorce. The Family Coordinator, 1976, $\underline{25}(2), 151-159$.

Fisher, E. Help for today's troubled marriages. New York: Hawthorn Books, 1968.

Fisher, E. Divorce: The new freedom. New York: Harper and Row, 1974.

Fitch, G. Effects of self-esteem, perceived performance, and choice on causal attribution. Journal of Personality and Social Psychology, $1970, \underline{16}(2), 3111-375$.

Forrester, R. Why we have to say good-bye. Canadian Psychiatric Association Journal, $1974, \underline{19}, 517-521$.

Galbraith, J.K. Economics and the quality of Tife. Science, 1964, 145(2), 117-123.

Gardner, R. The use of guilt as a defense against anxiety. The Psychoanalytic Review, 1970, 57(1), 124-135.

Gettleman, S., \& Markowitz, J. The courage of divorce. New York: Simon and Schuster, 1974.

Glick, P., \& Norton, A. Perspectives on the recent upturn in divorce and remarriage. Demography, 1973, 10, 307-314.

Glueck, E. Delinquents in the making. New York: Harper and Row Publishers, Inc., 1952.

Goldstein, J., \& Gitter, M. Divorce without blame. The Humanist, 1970 , $\underline{30}(3), 12-15$.

Goode, W. The family. Englewood Cliffs, New Jersey: Prentice-Ha11, 1964.

Goode, W. Women in divorce. New York: The Free Press, 1956. 
Hallett, K. A guide for single parents: Transactional analysis for people in crisis. Milbrae, California: Celestial Arts, 1974.

Halpern, H. Crisis theory: A definitional study. Community Mental Health Journal, $1973, \underline{9}(4), 342-349$.

Heider, $F$. The psychology of interpersonal relations. New York: John Wiley \& Sons, Inc., 1958.

Heritage, L. A study of selected factors and their effects on postdivorce adjustment. Unpublished Doctoral Dissertation, University of Southern Mississippi, 1971.

Herman, S. Divorce: A grief process. Perspectives in Psychiatric Care, $1974,12(3), 108-112$.

Hetherington, E.M.; Cox, M.; \& Cox, R. The aftermath of divorce. Unpublished manuscript, University of Virginia, 1976.

Hill, C.; Rubin, Z.; \& Peplau, L. Breakups before marriage: The end of 103 affairs. The Journal of Social Issues, $1976, \underline{32}(1), 147-$ 168.

Hochreich, D. Defensive externality and blame projection following failure. Journal of Personality and Social Psychology, 1975, $\underline{32}(3), 540-546$.

Holmes, T., \& Rahe, R. The social readjustment rating scale. Journal of Psychosomatic Research, 1967, 11(2), 213-218.

Horney, K. New ways in psychoanalysis. New York: W.W. Norton and Co., Inc., 1939.

Horney, K. The neurotic personality of our time. New York: McGraw-Hill, Book Co., 1966.

Hunt, M. The world of the formerly married. New York: McGraw-Hill Book Co., 1966 .

Jones, E.; Kanouse, D.; Kelley, H.; Nisbett, R.; Valins, S.; \& Weiner, B. Attribution: Perceiving the causes of behavior. Morristown, New Jersey: General Learning Press, 1972.

Kelley, H.H. Attribution theory in social psychology. In D. Levine (Ed.), Nebraska symposium on motivation. Lincoln, Nebraska: University of Nebraska Press, 1967.

Kelly, F.; Beggs, D.; \& McNeil, K. Research design in the behavioral sciences: Multiple regression approach. I1linois: Southern Illinois University Press, 1969. 
Kelly, J., \& Wallerstein, J. The effects of parental divorce: Experience of child in early latency. American Journal of Orthopsychiatry, $1976, \underline{46}(1), 20-32$.

Kerlinger, F., \& Pedhazur, E. Multiple regression analysis in behavioral research. New York: Holt, Rinehart and Winston, Inc., 1973.

Kessler, S. The American way of divorce. Chicago: Nelson-Ha11, 1975.

Krantzler, M. Creative divorce: A new opportunity for personal growth. New York: M. Evans and Co., Inc., 1973.

Kuntz, J., \& Miller, L. Prediction and statistical overkill revisited. Measurement of Evaluation in Guidance, 6 , 157-163.

Landis, J. The trauma of children when parents divorce. Marriage and Family Living, 1960, 22, 7-13.

Levinger, G., \& Moles, 0 . In conclusion: Threads in the fabric. Journal of Social Issues, 1976, 32(1), 193-207.

Loeb, J. The personality factor in divorce. Journal of Consulting Psychology, 1966, 30(6), 562 .

Lowe, L. Families of children with early childhood schizophrenia. Archives of General Psychiatry, 1966, 14, 26-30.

Lyman, H. Single again. New York: David McKay Co., Inc., 1971.

Malzberg, B. Marital status and the incidence of mental disease. Journal of Social Psychiatry, 1964, 10, 19-26.

Mazer, M. Two ways of expressing psychological disorder: The experience of a democrated population. American Journal of Psychiatry, $1972,128,933-938$.

McDermott, J. Parental divorce in early childhood. American Journal of Psychiatry, 1968, 124, 1424-1432.

Messer, A. Dissolution of long-standing marriages. Mental Hygiene, $1969, \underline{53}, 127-130$.

Messer, A. The Phaedra complex. Archives of General Psychiatry, 1969, 21, $213-218$.

Mosher, D. Fear and guilt in inhibiting unacceptable behavior. Journal of Consulting Psychology, 1965, 29(2), 161-167.

Mosher, D. The development of multitrait-multimethod matrix analysis of three measures of three aspects of guilt. Journal of Consulting and Clinical Psychology, 1966, 30, 25-29. 
Mosher, D. Measurement of guilt in females by self-report inventories. Journal of Consulting and Clinical Psychology, 1968, 32, 690695.

National Center for Health Statistics, Public Health Service, U.S. Department of H.E.W., National Vital Statistics System. Divorces: Analysis of changes, United States, 1969. Alexander A. Plateris. Series 21, No. 22. Rockville, Maryland: Health Services and Mental Health Administration, 1973.

Nie, N.; Hul1, C.; Jenkins, J.; Steinbrenner, K.; \& Bent, D. Statistical package for the social sciences. New York: McGraw-Hil 1 Book Co., 1975.

Norton, A., \& Glick, P. Marital instability: Past, present, and future. The Journal of Social Issues, $1976, \underline{30}(1), 5-20$.

Nunnal1y, J. Psychometric theory. New York: McGraw-Hi1l Book Co., 1967.

01 sen, N. The new testament logic on divorce. Tubingen: J.C.B. Mohr (Paul Siebuk), 1971.

Otterbacher, J.R., \& Munz, C.D. State-trait measure of experimental guilt. Journal of Consulting and Clinical Psychology, 1973, $\underline{40}(1), 115-121$.

Otterstrom, E. The social outlook for children of divorces. Acta Canet, $1952, \underline{3}, 72-96$.

Parad, H. Crisis intervention: Selected readings. New York: Family Service Association of America, 1972.

Paykel, E.; Prusoff, B.; \& Myers, I. Suicide attempts and recent 1ife events. Archives of General Psychiatry, 1975, 32, 327-333.

Pearlman, C. Separation reactions of married women. American Journal of Psychiatry, 1970, 126, 946-950.

Putney, R. Support systems of the separated/divorced. Unpublished Doctoral Dissertation, University of Massachusetts, 1975.

Rogers, L.; Young, H.; Cohen, I.; \& Dworin, J. Marital stability, mental health, and marital satisfaction. Journal of Consulting and Clinical Psychology, 1970, 35(3), 342-348.

Rogers, M. An introduction to the theoretical bas is of nursing. Philadelphia: F.A. Davis, 1970.

Rossi, A. Family development in a changing world. American Journal of Psychiatry, 1972, 128, 1057-1066. 
Ryder, R.; Kafka, J.; \& 01 son, D. Separating and joining influences in courtship and early marriage. American Journal of Orthopsychiatry, 1970, 41, 450-464.

Schwartz, S. Multimethod analysis of three measures of six common personality traits. Journal of Personality Assessment, 1973, 37, 559-567.

Sheffner, D., \& Swarez, J. The postdivorce clinic. American Journal of Psychiatry, 1975, 134, 442-444.

Short, J.F. Juvenile delinquency: The social-cultural context. In L. Hoffman and M. Hoffman (Eds.), Review of child development research, vol. 2. New York: Russell Sage Foundation, 1966.

Silverman, J. The women's liberation movement: Its impact on marriage. Hospital and Community Psychiatry, 1975, 26, 39-40.

Singer, L. Divorce and the single life: Divorce as development. Journal of Sex and Marital Therapy, 1975, 1, 254-262.

Skilbeck, W. Attributional change and crisis intervention. Psychotherapy Theory, Research and Practice, 1974, 11 (4), 371-375.

Smith, W.G. Critical life events and prevention strategies in mental health. Archives of General Psychiatry, 1971, 25, 103-109.

Spilken, A., \& Jacobs, M. Prediction of illness behavior from measures of life crisis, manifest distress and maladaptive coping. Psychosomatic Medicine, 1971, 33(3), 251-264.

Steinzor, B. When parents divorce: A new approach to new relationships. New York: Pantheon Books, 1969.

Tanner, I. Loneliness: The fear of love. New York: Harper and Row, Publishers, Inc., 1973.

Taube, C.A. National Institute of Mental Health Statistical Note 35. Survey and Reports Section, Biometry Branch, Office of Program Planning and Evaluation, December 1970.

Waller, W. The old love and the new. Illinois: Southern Illinois University Press, 1967.

Wallerstein, J., \& Kelly, J. The experiences of parental divorce: Experiences of the child in later latency. American Journal of Orthopsychiatry, 1976, 46(2), 256-269.

Walzer, S. Variations on certain frequently heard divorce themes. American Journal of Psychiatry, 1967, 123, 1169-1172. 
Watzlawick, P.; Beavin, J.; \& Jackson, D. Pragmatics of human communication. New York: W.W. Norton, 1967.

Weiss, R. The emotional impact of marital separation. The Journal of Social Issues, 1976, 32(1), 135-146.

Weiss, R. Marital separation. New York: Basic Books, Inc., 1975.

Westman, J.; Cline, D.; Swift, W.; \& Kramer, D. Role of child psychiatry in divorce. Archives of General Psychiatry, 1970, 23, 416-420.

Westman, J. The psychiatrist and child custody contests. American Journal of Psychiatry, 1971, 127, 1687-1688.

Whitaker, C., \& Miller, M. A reevaluation of psychiatric help. American Journal of Psychiatry, 1969, 126, 611-618.

Wiseman, R. Crisis theory and the process of divorce. Social Casework, $1975,205-212$.

Woodruff, R.A.; Guze, S.B.; \& Clayton, P.J. Divorce among psychiatric outpatients. British Journal of Psychiatry, 1972, 121, 289-292.

Wylie, H., \& Regado, R. A pattern of mother-son relationship involving the absence of the father. American Journal of Orthopsychiatry, $1959,29,644-649$. 


$$
\text { A P PENDIX A }
$$

MATERIALS FOR COLLECTION OF DATA 


\title{
INTRODUCTORY LETTER TO SUBJECTS
}

\author{
251 Pelham Road \\ Amherst, MA 01002 \\ (413) $253-7520$ \\ March 22, 1977
}

Dear :

Please excuse this form letter, but you are one of many people I want to contact to ask for help with a study I am conducting.

I am acutely aware of some of the difficulties and pain experienced by people undergoing divorce because I, myself, have been going through that process. Along with this personal experience, I am in the field of nursing and I have a real commitment to learning all I can to help others to make the most of such a difficult process.

I am thinking if we can pool our experience there is much that we can learn to help others who may face similar problems. So I have chosen this subject for my doctoral dissertation at the University of Massachusetts, and I expect to make it a major focus in my work in the future.

I obtained your name through the public records at the Probate Court of Hampshire County as part of a random sampling process. As you probably know, the fuller the response to the study, the more reliable and credible are the conclusions. So I surely hope you will respond.

What it would entail for you is probably an hour of your time to fill out three relatively brief questionnaires through the mail. Your responses would be completely anonymous.

I know this might be a little troublesome (because you might be busy, or because it might be painful to be reminded of the unpleasant aspect of your divorce, or because of countless other reasons). However, when I think of what we may be able to learn to make it easier for others in the future, I hope you will figure it is worth it.

I would be glad to share the results of the study with you if you like. Just write or call me some time this summer. I should have our experiences pretty well summarized by then.

In a couple of weeks I will mail you the questionnaires. I surely will appreciate your help in the study.

Sincerely yours,

Linda Ceriale, R.N., M.A. 


\section{COVER LETTER WITH QUESTIONNAIRE PACKET}

215 Peiham Road

Amherst, MA 01002

(413) $253-7520$

March 31, 1977

Dear :

Here are the questionnaires I told you I would send. I also enciosed a stamped addressed envelope to make it easier for you to return the questionnaires.

Again let me assure you that your responses are completely anonymous. I would like you to answer all questions though some may be very difficult. Also, the results will be meaningful only to the extent that you can reveal your true feelings in your answers. So please try to be as sincere and candid as possible.

If you do not wish to answer any question, I would prefer that you leave it blank rather than slant your response in any way. And of course, if you want to expand on any of the short responses asked for, feel free to write on the back or append another page with your thoughts on it.

I thank you in advance for joining in this endeavor. If you want to hear what I have learned from our collective effort, let me know. I expect I will receive your response within the next couple of weeks so that I will be able to summarize our experiences by midsummer. Contact me then if you wish.

Sincerely yours,

Linda Ceriale, R.N., M.A.

Enclosures 


\section{GENERAL INFORMATION QUESTIONNAIRE}

Please answer the following questions by checking appropriate space or filling in blank.

1. Sex: male female

2. Remarried: yes no

3. Age:

4. Employed: yes no

5. Religious: yes no

6. Yearly Income:

7. Did you initiate divorce proceedings? yes no

8. Number of marriages:

9. Number of children:

10. Number of years married to your most recent ex-spouse:

11. Number of months from your obtaining the temporary divorce decree (divorce nisi):

12. Do you presently have an intimate relationship in your life? (By intimate I mean valuing another with whom you find a satisfying fulfillment of each other's general needs, and for whom you feel a deep liking and deep respect as a human being.) yes If more than one, how many? no

13. Please indicate who and/or what events or things were responsible for your marriage terminating. Just one may have been responsible or many. The following people, things, and events are given as suggestions. Feel free to write down any others on the lines provided. In indicating who or what was responsible, please indicate by placing percentage amounts on the space to the right. The percentage must add up to 100 .

yourself

your ex-spouse

your children

your job others members of your family members of your ex-spouses' family finances luck luck your ex-spouse's job

14. Possibly you regard the end of your marriage as due to no particular causes, but only the eventual outcome of you and your ex-spouse slowly growing apart. yes no 
15. Regardless of who or what was responsible, does your breakup leave you feeling:

\begin{tabular}{l|c|c|c|c|c|} 
worthless & $\begin{array}{c}\text { of little } \\
\text { worth }\end{array}$ & $\begin{array}{c}\text { slightly be low } \\
\text { average worth }\end{array}$ & $\begin{array}{c}\text { slightly above } \\
\text { average worth }\end{array}$ & $\begin{array}{l}\text { of substan- } \\
\text { tial worth }\end{array}$ & $\begin{array}{c}\text { of great } \\
\text { worth }\end{array}$ \\
\hline 1. & 2.
\end{tabular}

16. Regardless of who or what was responsible, do you consider your exspouse

\begin{tabular}{l|c|c|c|c|c|c|} 
worthless & $\begin{array}{c}\text { of little } \\
\text { worth }\end{array}$ & $\begin{array}{c}\text { slightly below } \\
\text { average worth }\end{array}$ & $\begin{array}{c}\text { slightly above } \\
\text { average worth }\end{array}$ & $\begin{array}{c}\text { of substan- } \\
\text { tial worth }\end{array}$ & $\begin{array}{l}\text { of great } \\
\text { worth }\end{array}$ \\
\hline 1. & 2.
\end{tabular}

17. Regardless of who or what was responsible for the breakup, I feel \begin{tabular}{c|c|c|c|c|c}
$\begin{array}{c}\text { very } \\
\text { unhappy }\end{array}$ & $\begin{array}{c}\text { unhappy } \\
\text { with myself }\end{array}$ & $\begin{array}{c}\text { slightly } \\
\text { unhappy }\end{array}$ & $\begin{array}{c}\text { slightly } \\
\text { happy }\end{array}$ & happy & very happy \\
with myself & with myself & with myself & with myself \\
\hline
\end{tabular}
1.
2.
3.
4.
5.
6.

You might like to use this page to write any comments you may want to share about your particular experience with divorce. Please feel free, also, to make any comments at all about the questionnaires. 
TASK AND EXPERIENCE QUESTIONNAIRE

Directions:

The following statements describe how you might feel or act in particular situations. Following each statement is a numbered scale from 1 to 11 which corresponds to how often you may feel or act that way from never to always. For each statement please indicate in the space provided next to the number on the scale how often you may have felt or acted that way during your marriage in general prior to this divorce, how often you feel or act that way now, and how often you would prefer to feel or act that way now or in the immediate future.

Please use the following letters in the particular space you choose for each of the statements:

$$
\begin{aligned}
M=\text { marriage }= & \text { How often you felt or acted that way during your } \\
& \text { past marriage in general before the marriage became } \\
& \text { problematic. }
\end{aligned}
$$

There are no right or wrong answers, of course. Furthermore, all sorts of combinations of how you felt or acted during your past marriage, how you feel or act now, and how you would prefer to feel or act are possible. In other words, you may place the $M, N, P$ in the same space on the scale or they may be spread out.

The following possible responses may serve to help clarify that point: 
6. When problems arise for me and I cannot solve them myself, I have a close friend or family member who I turn to for help when I need it.

NEVER SELDOM SOMETIMES MODERATELY OFTEN VERY OFTEN ALWAYS

$1+2 \quad 3 \quad 4 \quad 5 \quad 6 \quad 7 \quad 8 \quad 9 \quad 9 \quad 10 \quad 11$

7. I smoke cigarettes.

NEVER SELDOM SOMETIMES MODERATELY OFTEN VERY OFTEN ALWAYS

$1 \_2 \quad 3 \quad 4 \quad 5 \quad 6 \quad 7 \quad 8 \quad 9 \quad 9 \quad 10 \quad 11$

8. I feel uncomfortable in the presence of my ex-spouse.

NEVER SELDOM SOMETIMES MODERATELY OFTEN VERY OFTEN ALWAYS

$1 \_2 \quad 3 \quad 4 \quad 5 \quad 6 \quad 6 \quad 7 \quad 8 \quad 9 \quad 9 \quad 10 \quad 11$

9. I am satisfied with the way I express my feelings.

NEVER SELDOM SOMETIMES MODERATELY OFTEN VERY OFTEN ALWAYS

$1+2 \quad 3 \quad 4 \quad 5 \quad 6 \quad 7 \quad 8 \quad 8 \quad 9 \quad 10 \quad 11$

10. If I feel like going out (for example: to a movie, restaurant, museum) and there is no one to go with me at the time, then I rather stay home than go by myself.

NEVER SELDOM SOMETIMES MODERATELY OFTEN VERY OFTEN ALWAYS

$1+2 \quad 3 \quad 4 \quad 5 \quad 6 \quad 6 \quad 7 \quad 8 \quad 8 \quad 9 \quad 10 \quad 11$

11. If I cannot solve problems which pertain to my child or children, I know or will find out where I can get help to solve them.

NEVER SELDOM SOMETIMES MODERATELY OFTEN VERY OFTEN ALWAYS

$1+2 \quad 3 \quad 4 \quad 5 \quad 6 \quad 6 \quad 7 \quad 3 \quad 8 \quad 9 \quad-10 \quad 11$

12. I do the household chores (for example: cooking, cleaning, laundry, shopping) by myself or get help from others when necessary.

NEVER SELDOM SOMETIMES MODERATELY OFTEN VERY OFTEN ALWAYS

$\begin{array}{lllllllll}1 & 2 & 3 & 4 & 5 & 6 & 7 & 8 & 9\end{array}$

13. It bothers me to be alone.

\begin{tabular}{lccccccc} 
NEVER & SELDOM & SOMETIMES MODERATELY OFTEN VERY OFTEN ALWAYS \\
\hline & 2 & 3 & 4 & 5 & 6 & 7 & 8
\end{tabular}


14. I drink alcoholic beverages.

\begin{tabular}{llllll} 
NEVER & SELDOM SOMETIMES MODERATELY OFTEN VERY OFTEN ALWAYS \\
\hline & 2 & 3 & 4 & 5 & 6
\end{tabular}

5. I am able to handle my financial matters by myself (for example:

through employment) or through the aid of others (for example: welfare, aid to dependent children, food stamps, alimony).

NEVER SELDOM SOMETIMES MODERATELY OFTEN VERY OFTEN ALWAYS

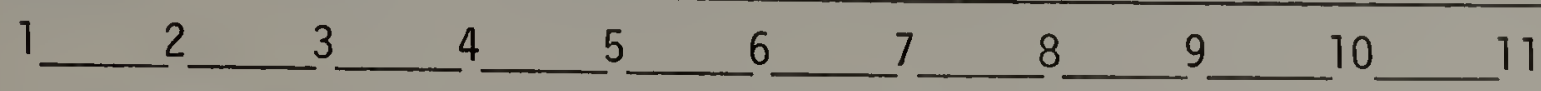

16. Worrying during the day interferes with my household chores (cooking, cleaning, laundry, shopping) or my performance at my job.

NEVER SELDOM SOMETIMES MODERATELY OFTEN VERY OFTEN ALWAYS

$1+2 \quad 3 \quad 4 \quad 5 \quad 5 \quad 6 \quad 5 \quad 8 \quad 8 \quad 9 \quad-10 \quad 11$

17. If I have been invited to a party or other social gathering and there is no one to go with me at the time, then I would go by myself.

\begin{tabular}{|c|c|c|c|c|c|c|}
\hline NEVER & SELDOM & SOMETIMES & MODERATELY & OFTEN & VERY OFTEN & ALWAYS \\
\hline 1 & 3 & 5 & 6 & 8 & 10 & 7 \\
\hline
\end{tabular}

18. I wake up in the morning with general fatigue.

NEVER SELDOM SOMETIMES MODERATELY OFTEN VERY OFTEN ALWAYS

$1 \_2 \quad 3 \quad 4 \quad 4 \quad 5 \quad 6 \quad 6 \quad 7 \quad 8 \quad 8 \quad 9 \quad-10 \quad 11$

19. I am comfortable with myself as a sex partner.

NEVER SELDOM SOMETIMES MODERATELY OFTEN VERY OFTEN ALWAYS

$1+2 \quad 3 \quad 4 \quad 5 \quad 5 \quad 6 \quad 7 \quad 8 \quad 8 \quad 9 \quad 10 \quad 11$

20. I have confidence in myseif.

NEVER SELDOM SOMETIMES MODERATELY OFTEN VERY OFTEN ALWAYS

\begin{tabular}{lllllllll}
\hline & 2 & 3 & 4 & 5 & 6 & 7 & 8 & 9
\end{tabular}

21. I have difficulty expressing my opinions.

\begin{tabular}{lccccccc} 
NEVER & SELDOM & SOMETIMES & MODERATELY OFTEN VERY OFTEN ALWAYS \\
\hline & 2 & 3 & 4 & 5 & 6 & 7 & 8
\end{tabular}




\section{FEELING AND ATTITUDE QUESTIONNAIRE}

Directions:

Please read each of the following statements and decide whether it is true as applied to you or false as applied to you (or whether you agree with the opinions expressed or disagree with the opinions expressed). If a statement is TRUE or MOSTLY TRUE as applied to you (or if you AGREE or MOSTLY AGREE with the opinion expressed), circle the $T$ to the right of the statement. If a statement is FALSE or MOSTLY FALSE as applied to you (or if you DISAGREE or MOSTLY DISAGREE with the opinion expressed), circle the $F$ to the right of the statement. There are no right or wrong answers--just give your own opinion.

1. WHEN ANGER BUILDS INSIDE me I usually explode.

1. $T$ F

2. A GUILTY CONSCIENCE is a good thing, it is our mental

2. $T$ F thermostat.

3. WOMEN WHO CURSE are normal.

3. $T$ F

4. PROSTITUTION is a sign of moral decay in society.

4. $T \quad F$

5. IF I KILLED SOMEONE IN SELF DEFENSE, I would stili be

5. $\mathrm{T} F$ troubled by my conscience.

6. "DIRTY" JOKES IN MIXED COMPANY makes them more

6. $\mathrm{T} F$ interesting.

7. AFTER AN ARGUMENT I usually feel better.

7. $T$ F

8. THE IDEA OF MURDER is something I have never had.

8. $T \quad F$

9. I TRIED TO MAKE AMENDS for al1 my misdeeds, but I

9. $\mathrm{T} F$ can't forget them.

10. I DETEST MYSELF for nothing, I love life.

10. $\mathrm{T} F$

11. AFTER AN OUTBURST OF ANGER I curse myself for not

11. $\mathrm{T} F$ having control. 
12. WHEN I HAVE SEXUAL DESIRES I usually try to curb them. 12. T F

13. I REGRET that I was not born rich. $13 . T \quad F$

14. OBSCENE LITERATURE is a sinful and corrupt business. 14. T F

15. IF I KILLED SOMEONE IN SELF DEFENSE, I would $15 . T \quad F$ consider myself lucky.

16. WHEN I TELL A LIE it hurts.

17. WHEN SOMEONE SWEARS AT ME I swear back.

18. MASTURBATION is fun.

19. TO KILL IN WAR is good and meritable.

20. SEX RELATIONS BEFORE MARRIAGE are practiced too much to be wrong.

16. $\mathrm{T} F$

17. $T F$

18. $T \quad F$

19. $T \quad F$

20. T F

21. IF I HAD SEX RELATIONS I would feel a lot less bored. 21. $T$ F

22. AS A CHILD, SEX PLAY is not good for mental and 22. $T F$ emotional health.

23. AFTER AN OUTBURST OF ANGER I usually feel quite a $23 . \quad T \quad F$ bit better.

24. WHEN I HAVE SEXUAL DESIRES I generally satisfy them.

25. CAPITAL PUNISHMENT should be abolished.

25. $T F$

26. AFTER AN ARGUMENT I feel mean.

26. $T F$

27. WHEN I TELL A LIE I make it a good one.

27. $T F$

28. THE IDEA OF MURDER is nauseating.

28. $T F$ 29. I TRIED TO MAKE AMENDS as soon after the argument as
I could.

29. $T F$

30. IF IN THE FUTURE I COMMITTED ADULTERY I Would

30. $\mathrm{T} F$ probably feel bad about it.

31. UNUSUAL SEX PRACTICES might be interesting.

31. $\mathrm{T} F$

32. AS A CHILD, SEX PLAY is natural and innocent.

32. $T F$

33. A GUILTY CONSCIENCE does not bother me too much.

33. $\mathrm{T} F$ 
34. WOMEN WHO CURSE make me sick.

35. OBSCENE LITERATURE is detrimental to society.

36. PROSTITUTION shoutd be legalized.

37. "DIRTY" JOKES IN MIXED COMPANY are not proper.

38. AFTER AN ARGUMENT I feel proud in victory.

39. WHEN I TELL A LIE it is an exception or rather an odd occurrence.

40. MASTURBATION is all right.

41. I COULD NOT DO IT BECAUSE I got an attack of conscience or cold feet.

42. PETTING, I AM SORRY TO SAY, is becoming an accepted practice.

43. OBSCENE LITERATURE is fascinating reading.

44. "DIRTY" JOKES IN MIXED COMPANY are lots of fun.

45. SEX RELATIONS BEFORE MARRIAGE ruin many a happy couple.

46. UNUSUAL SEX PRACTICES are $0 . k$. as long as they're heterosexual.

47. AFTER AN OUTBURST OF ANGER I realize that I have done wrong.

48. CAPITAL PUNISHMENT is totally acceptable for a capital crime.

49. IF I HATED MY PARENTS I would rebel at their every wish.

50. WHEN I TELL A LIE I'm angry with myself.

51. AFTER A CHILDHOOD FIGHT, I felt mad and irritable.

52. SIN AND FAILURE are disgusting.

53. IF I ROBBED A BANK I would live like a king.

54. IF I FELT LIKE MURDERING SOMEONE I'd think I was crazy.
34. $T \quad F$

35. $T \quad F$

36. $T F$

37. $T \quad F$

38. $T F$

39. $T F$

40. $T F$

41. $T F$

42. $T F$

43. $\mathrm{T} F$

44. $T F$

45. $T F$

46. $T$ F

47. $\mathrm{T} F$

48. $T \quad F$

49. $\mathrm{T} F$

50. $\mathrm{T} F$

51. $T \quad F$

52. $\mathrm{T} F$

53. $\mathrm{T} F$

54. $\mathrm{T} F$ 
55. I HATE sin.

56. WHEN I HAVE SEXUAL DESIRES they are usually quite strong.

57. WHEN I TELL A LIE I mix it with truth and serve it like a Martini.

58. AFTER A CHILOHOOD FIGHT, I felt miserable and made up afterwards.

59. IF IN THE FUTURE I COMMITTED ADULTERY I would be ashamed but not say anything about it.

60. TO KILL IN WAR would be sickening to me.

61. ARGUMENTS LEAVE ME FEELING $i 11$ at ease and ready to renew a friendship.

62. I DETEST MYSELF for nothing, and only rarely dislike 62. T F myself.

63. AFTER AN OUTBURST OF ANGER I feel ridiculous and sorry 6 that I showed my emotions.

64. WOMEN WHO CURSE are foul mouthed females--not women.

65. AFTER AN ARGUMENT I am sorry for my actions.

66. WHEN SOMEONE SWEARS AT ME it usually bothers me even if I don't show it.

67. IF IN THE FUTURE I COMMITTED ADULTERY I won't feel bad about it.

68. SEX RELATIONS BEFORE MARRIAGE are good in my opinion.

69. I DETEST MYSELF for thoughts I sometimes have.

70. CAPITAL PUNISHMENT is playing God.

71. OBSCENE LITERATURE should be freely published.

72. I TRIED TO MAKE AMENDS with my God and Soul.

73. I PUNISH MYSELF with guilty feelings.

74. ARGUMENTS LEAVE ME FEELING as if they never should have been started.

75. AFTER AN OUTBURST OF ANGER I am sorry and say so.
55. $T \quad F$

56. $T F$

57. $\mathrm{T} F$

58. $T F$

59. $\mathrm{T} F$

60. $\mathrm{T} F$

61. T F

63. $T F$ 64. T F

65. $T F$

66. $\mathrm{T} F$

67. $\mathrm{T} F$

68. $\mathrm{T} F$

69. $\mathrm{T} F$

70. $\mathrm{T} F$

71. $T$ F

72. $\mathrm{T} F$

73. $\mathrm{T} F$

74. $\mathrm{T} F$

75. $T \quad F$ 
A P P E D I X B

DATA 


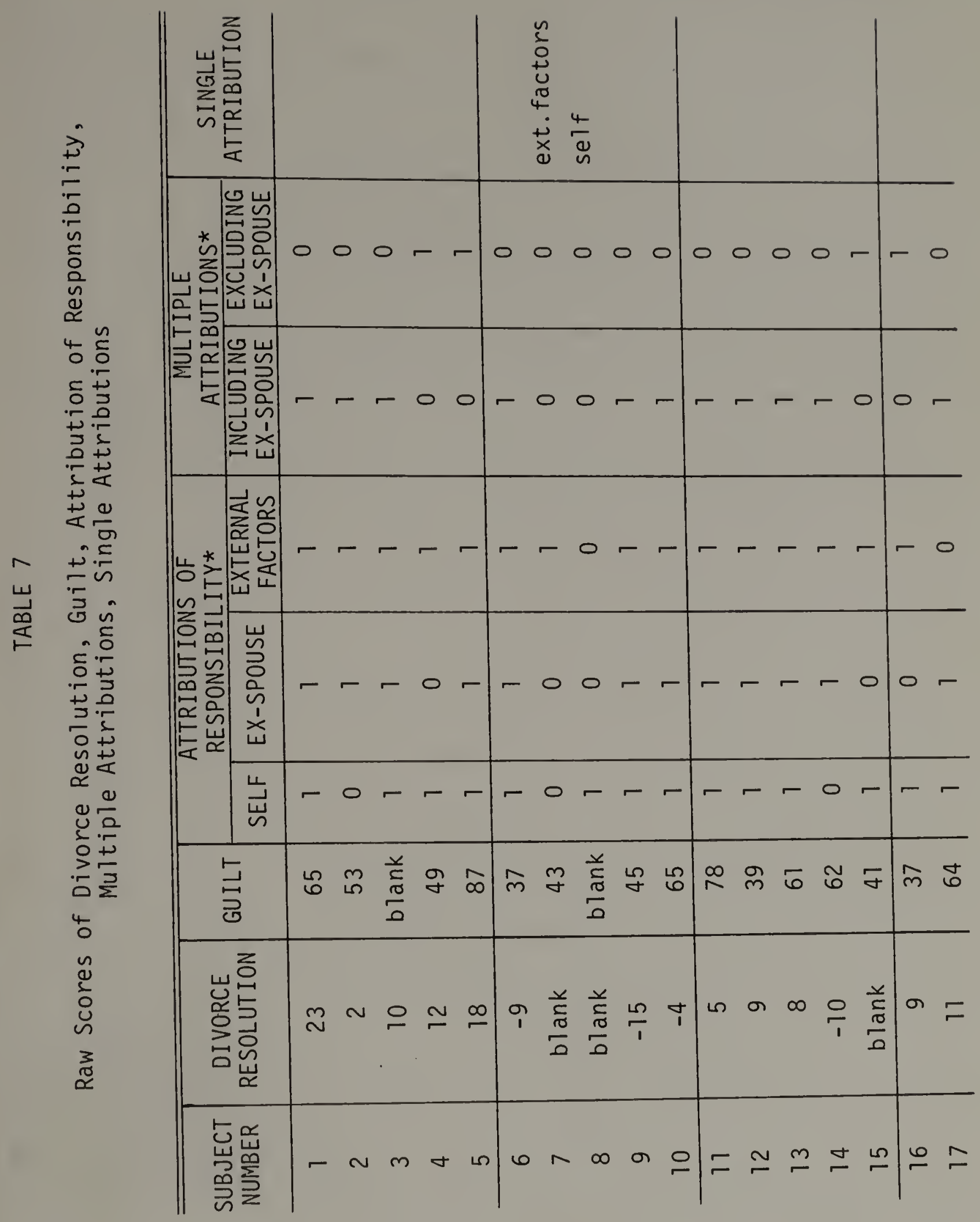




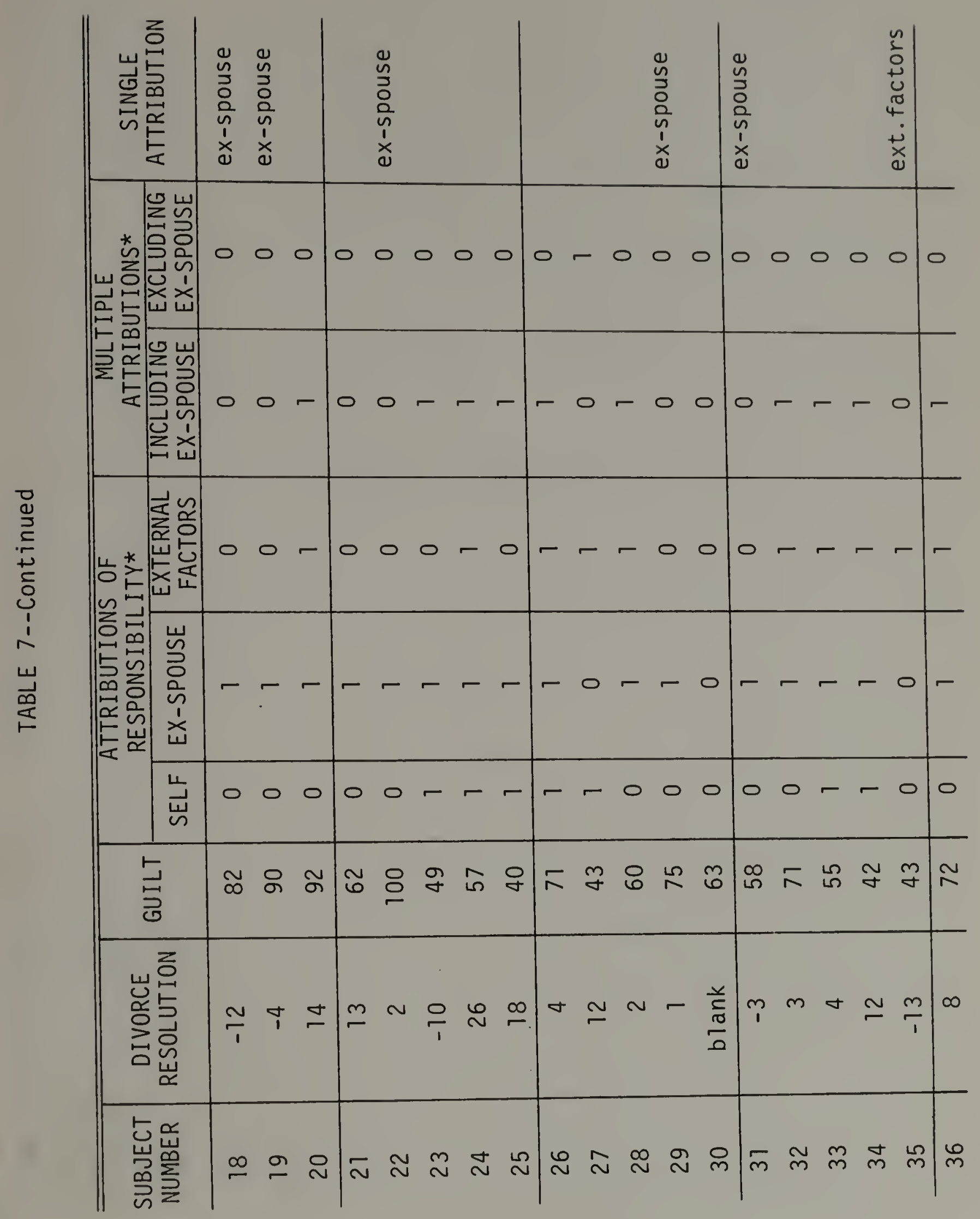




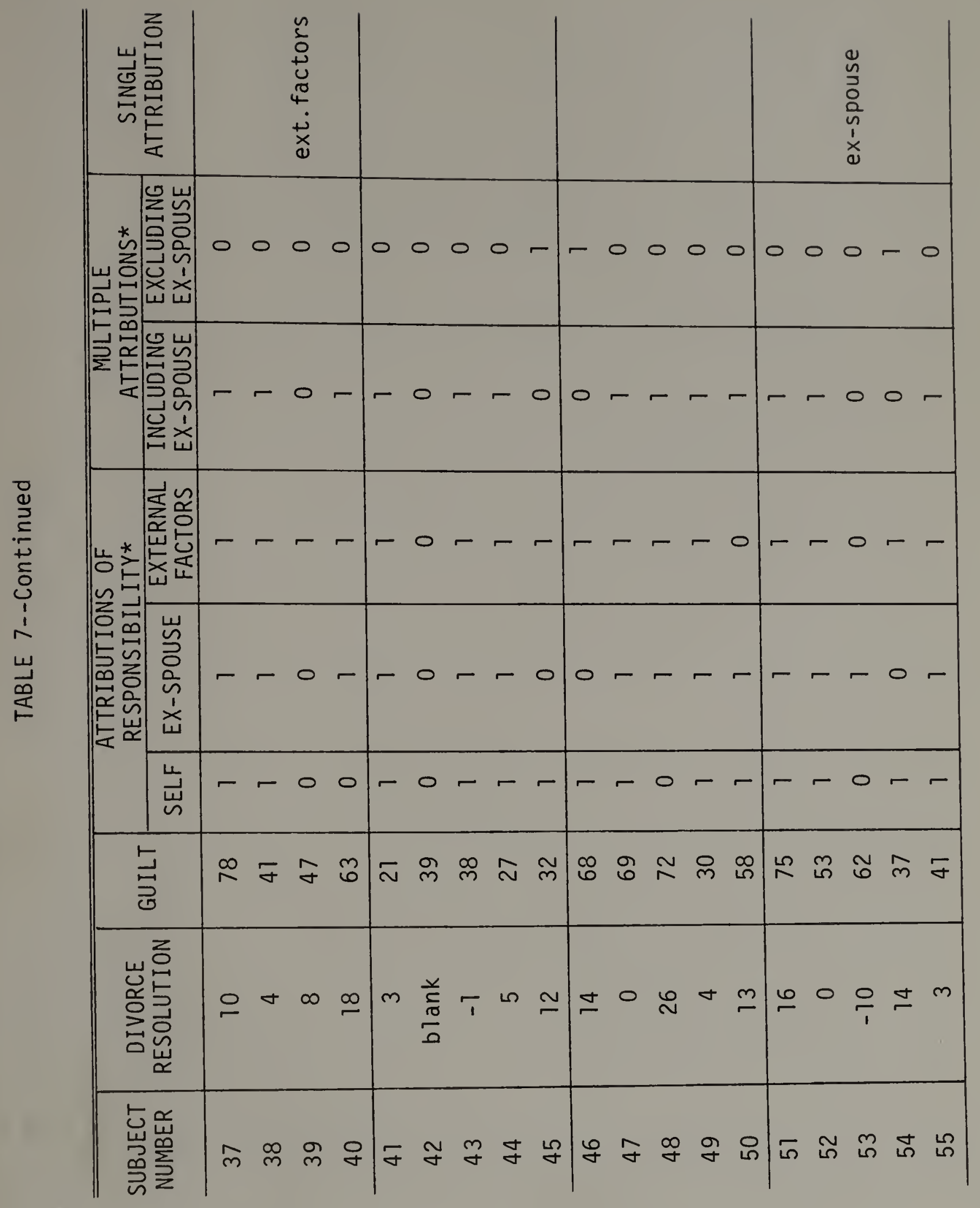




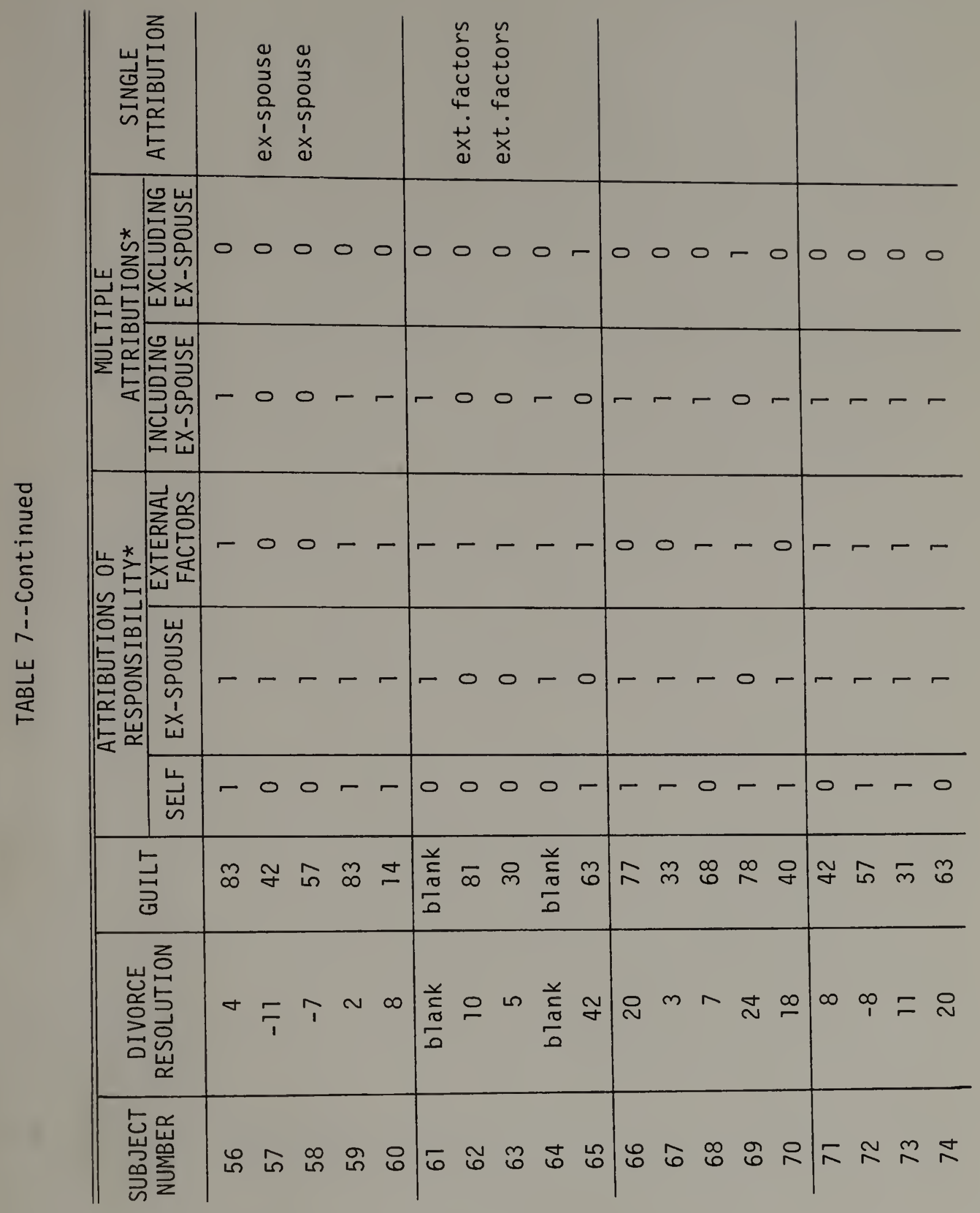




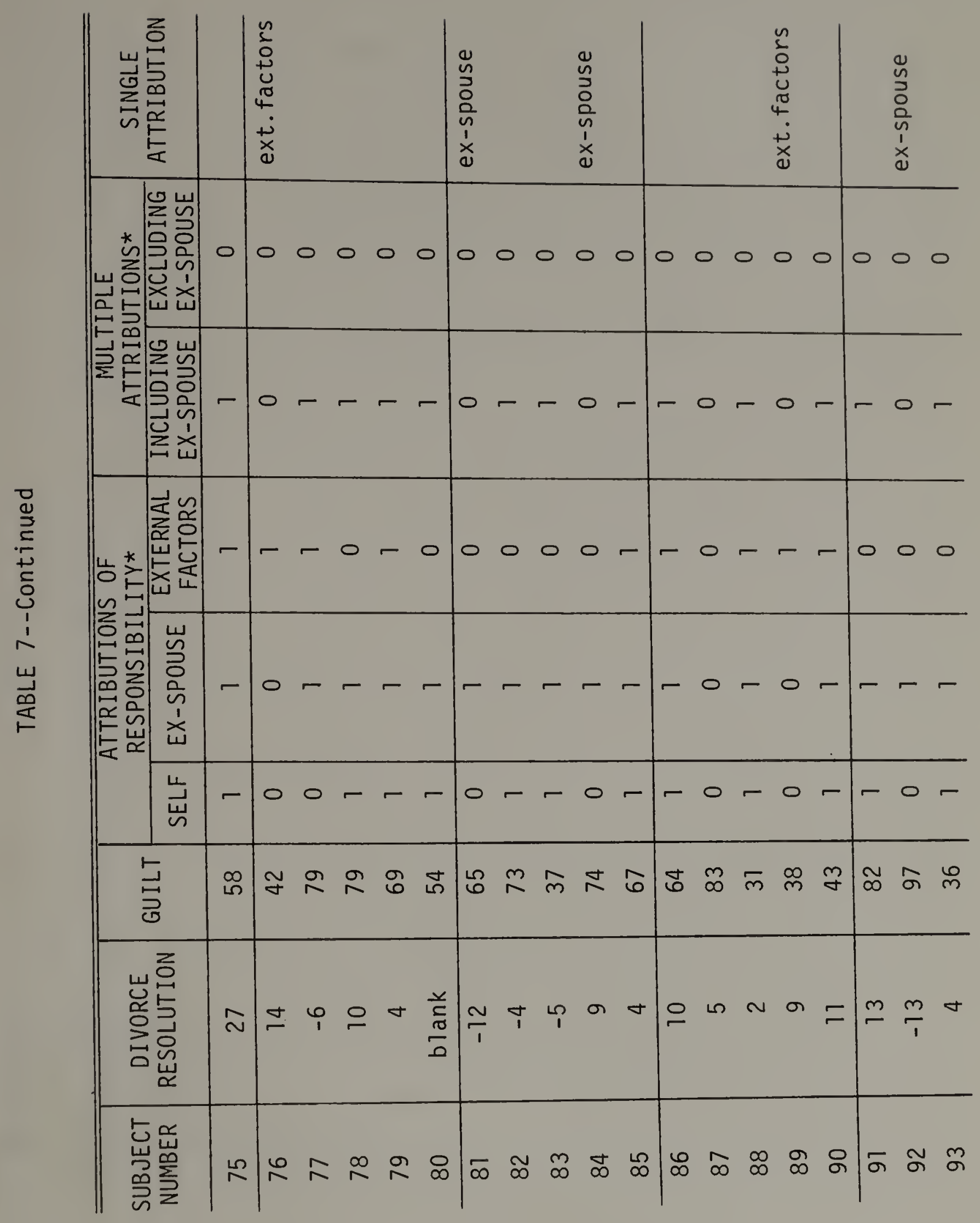




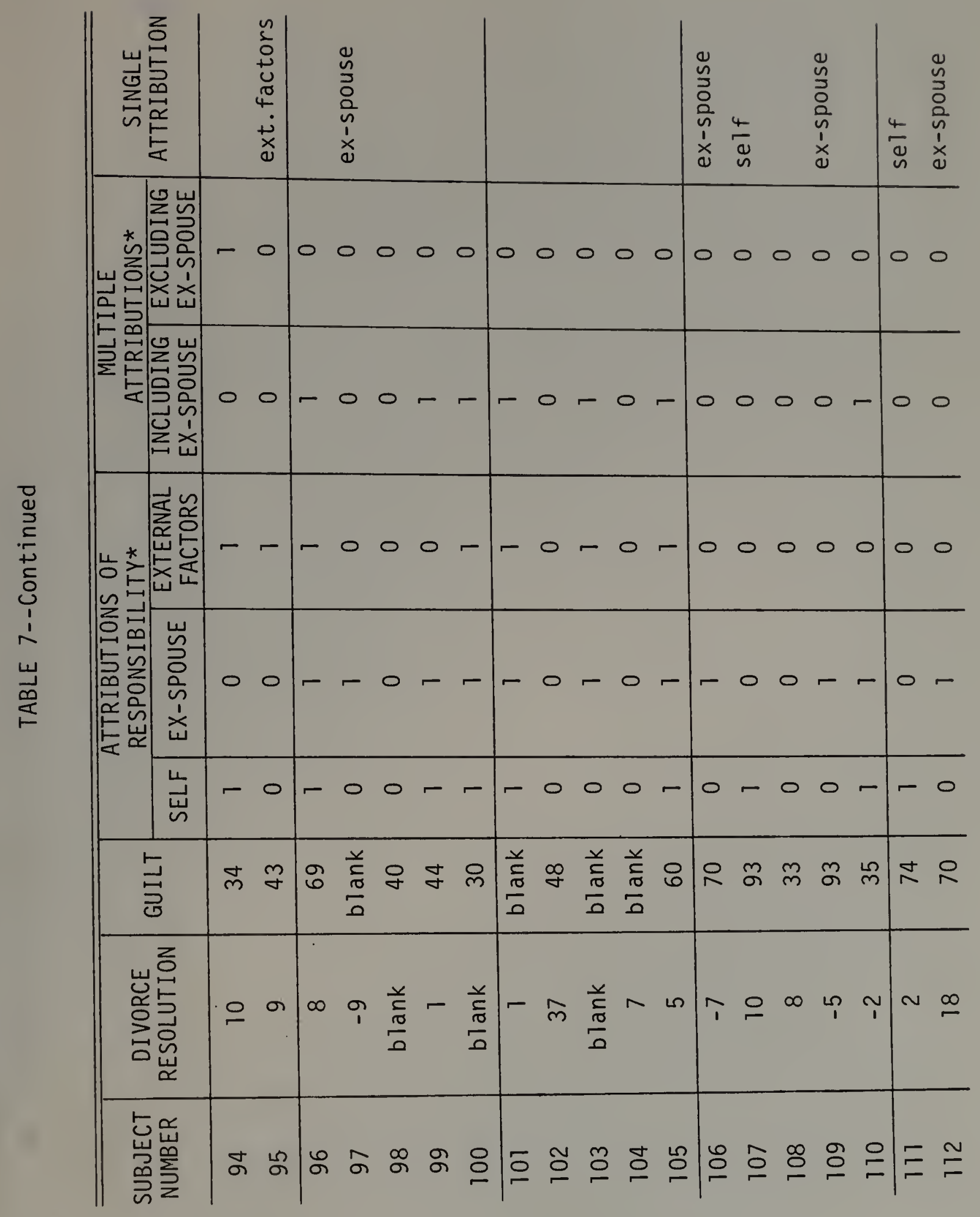




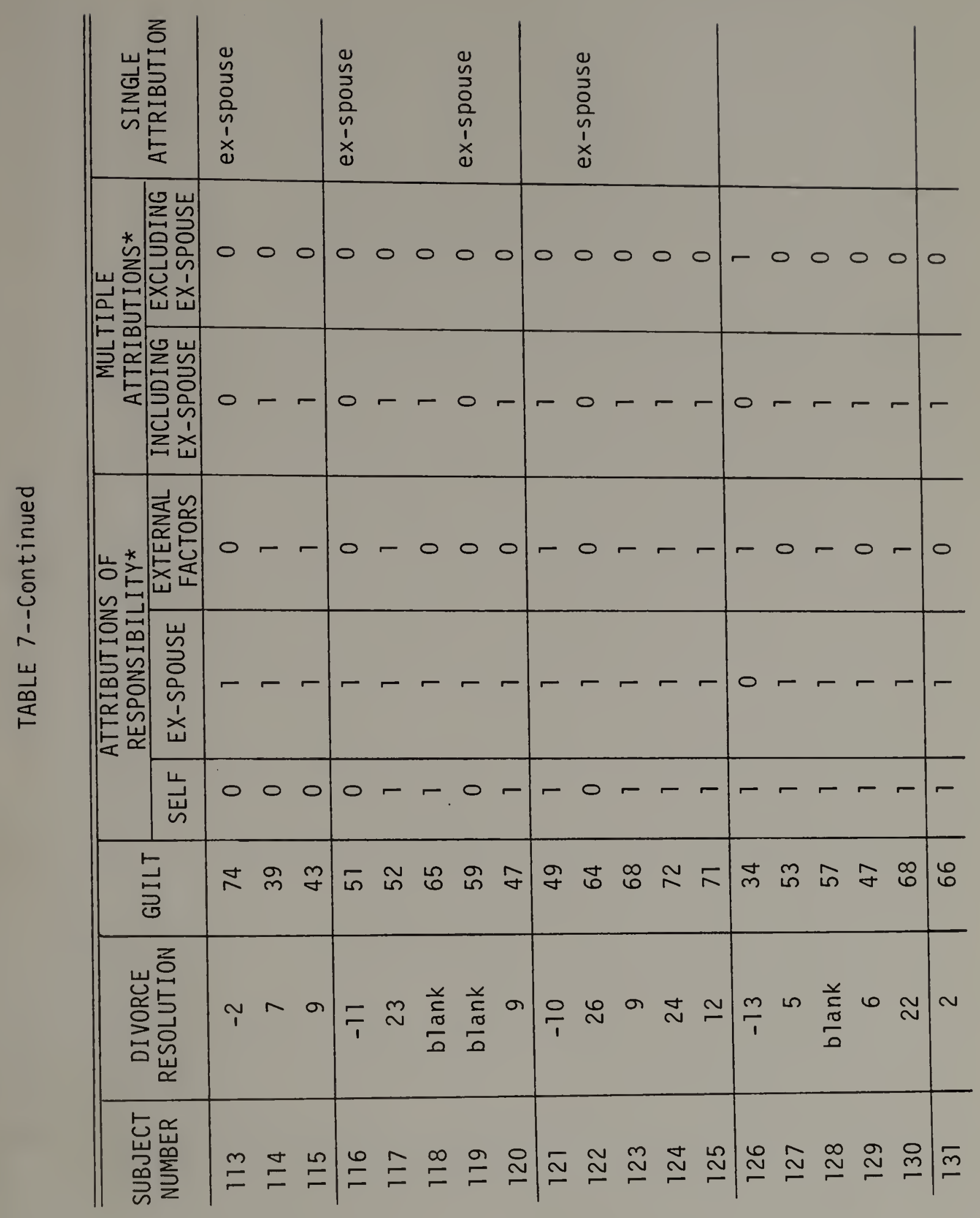




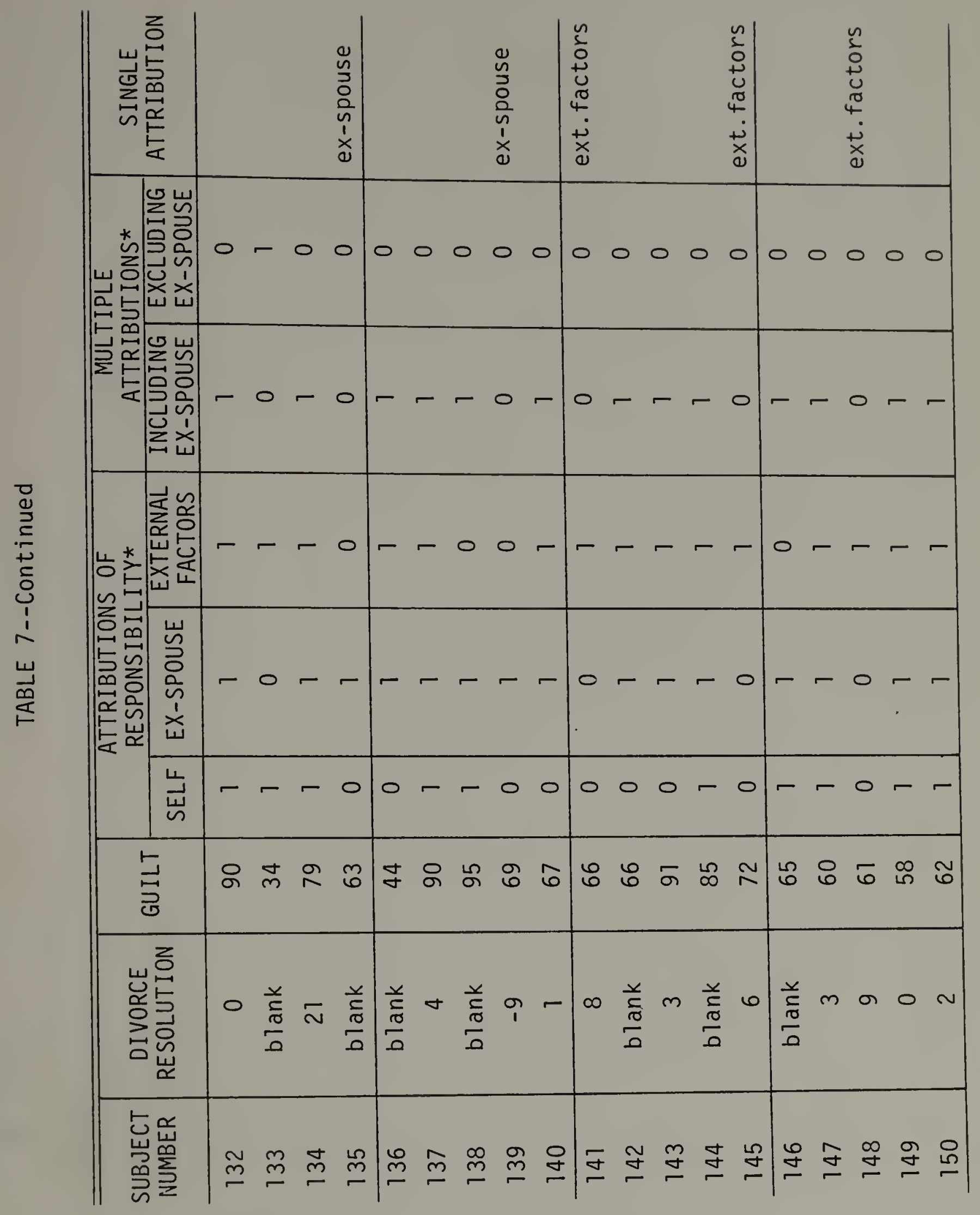




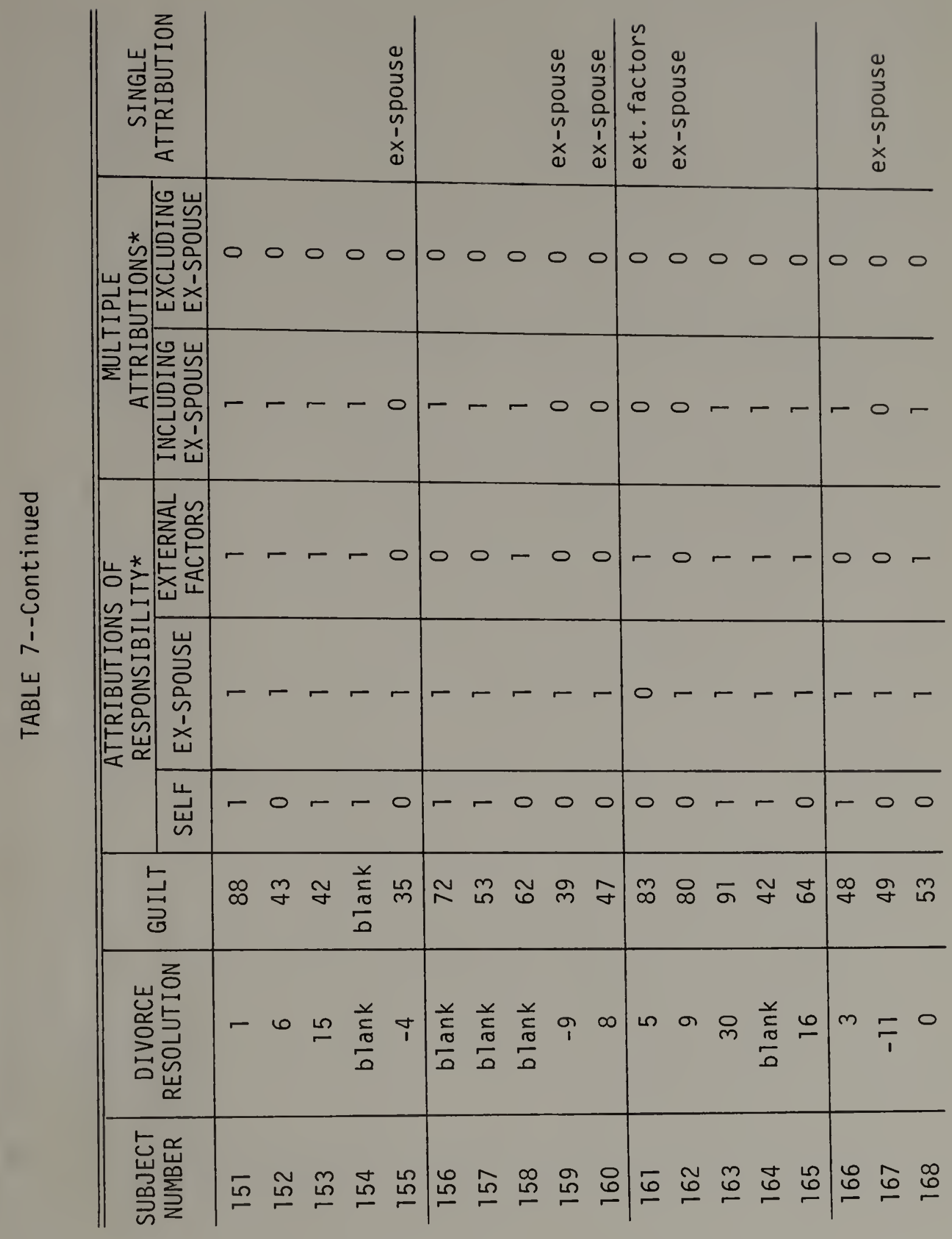




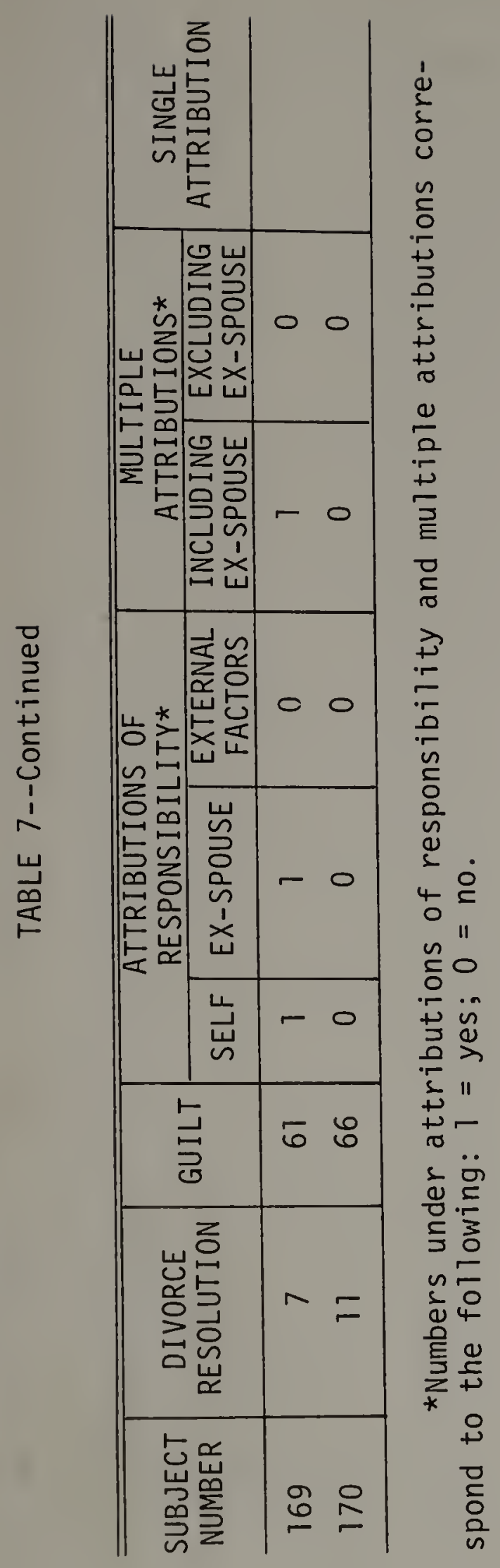


TABLE 8

Frequency of Data on Characteristics of Sample

\begin{tabular}{|c|c|c|}
\hline CHARACTERISTICS & NUMBER OF CASES & ADJUSTED PERCENTAGES \\
\hline $\begin{array}{l}\frac{\text { Sex }}{\text { Male }} \\
\text { Female } \\
\text { Blank }\end{array}$ & $\begin{array}{r}66 \\
103 \\
1\end{array}$ & $\begin{array}{l}39 \\
61\end{array}$ \\
\hline $\begin{array}{l}\frac{\text { Age }}{20}-24 \\
25-29 \\
30-34 \\
35-39 \\
40-44 \\
45-49 \\
50-54 \\
55-59 \\
\text { Blank }\end{array}$ & $\begin{array}{r}22 \\
65 \\
44 \\
14 \\
8 \\
7 \\
5 \\
3 \\
2\end{array}$ & $\begin{array}{r}13 \\
39 \\
26 \\
8 \\
5 \\
4 \\
3 \\
2\end{array}$ \\
\hline $\begin{array}{l}\text { Employed } \\
\text { Yes } \\
\text { No } \\
\text { Blank }\end{array}$ & $\begin{array}{r}119 \\
50 \\
1\end{array}$ & $\begin{array}{l}70 \\
30\end{array}$ \\
\hline $\begin{array}{l}\text { Religious } \\
\text { Yes } \\
\text { No } \\
\text { Blank }\end{array}$ & $\begin{array}{r}64 \\
97 \\
9\end{array}$ & $\begin{array}{l}40 \\
60\end{array}$ \\
\hline $\begin{array}{l}\text { Months Since Divorce } \\
6-8 \\
9-11 \\
12-14 \\
15-17 \\
\text { B1ank }\end{array}$ & $\begin{array}{l}27 \\
43 \\
45 \\
39 \\
28\end{array}$ & $\begin{array}{l}19 \\
28 \\
31 \\
22\end{array}$ \\
\hline $\begin{array}{c}\text { Years Married } \\
1-3 \\
4-6 \\
7-9 \\
10-12 \\
13-15 \\
16-18 \\
19-21 \\
22-24 \\
25-27 \\
28-32\end{array}$ & $\begin{array}{r}36 \\
53 \\
36 \\
17 \\
16 \\
8 \\
2 \\
1 \\
4 \\
2\end{array}$ & $\begin{array}{r}21 \\
31 \\
21 \\
10 \\
6 \\
5 \\
1 \\
2 \\
2 \\
1\end{array}$ \\
\hline
\end{tabular}


TABLE 8--Continued

\begin{tabular}{|c|c|c|}
\hline CHARACTERISTICS & NUMBER OF CASES & ADJUSTED PERCENTAGES \\
\hline \multicolumn{3}{|l|}{ Remarried Since Divorce } \\
\hline & 7 & 4 \\
\hline No & 163 & 96 \\
\hline \multicolumn{3}{|l|}{ Number of Children } \\
\hline None & 44 & 26 \\
\hline 1 & 42 & 25 \\
\hline 2 & 43 & 25 \\
\hline & 20 & 12 \\
\hline & 12 & 7 \\
\hline 5 & 3 & 2 \\
\hline $6-8$ & 5 & 3 \\
\hline \multicolumn{3}{|l|}{ Number of Marriages } \\
\hline & 132 & 78 \\
\hline 2 & 34 & 19 \\
\hline 3 & 3 & 2 \\
\hline 5 & 1 & 1 \\
\hline \multicolumn{3}{|l|}{ Income } \\
\hline $0-4,999$ & 31 & 22 \\
\hline $5,000-9,999$ & 40 & 28 \\
\hline $10,000-14,999$ & 44 & 32 \\
\hline $15,000-19,999$ & 12 & 12 \\
\hline $20,000-24,999$ & 4 & 3 \\
\hline $25,000-29,999$ & 4 & 3 \\
\hline Blank & 35 & \\
\hline \multicolumn{3}{|l|}{ Initiator of Divorce Proceedings } \\
\hline Yes & 107 & $\begin{array}{l}65 \\
35\end{array}$ \\
\hline & 57 & \\
\hline Blank & 6 & \\
\hline \multicolumn{3}{|l|}{ Have Intimate Relationship } \\
\hline Yes & $\begin{array}{r}118 \\
50\end{array}$ & $\begin{array}{l}70 \\
30\end{array}$ \\
\hline $\begin{array}{l}\text { No } \\
\text { Blank }\end{array}$ & 2 & \\
\hline \multicolumn{3}{|l|}{ Feeling Worthy Toward Self } \\
\hline Worthless or Little Worth & 20 & 12 \\
\hline Slightly Below Average Worth & 23 & 14 \\
\hline STightly Above Average Worth & 17 & $\begin{array}{l}11 \\
63\end{array}$ \\
\hline $\begin{array}{l}\text { Substantial Worth or Great Worth } \\
\text { Blank }\end{array}$ & $\begin{array}{r}104 \\
6\end{array}$ & \\
\hline
\end{tabular}


TABLE 8--Continued

\section{CHARACTERISTICS}

NUMBER OF CASES ADJUSTED PERCENTAGES

Feel ing Worthy Toward Ex-Spouse

Worthless or Little Worth Slightly Below Average Worth Slightly Above Average Worth Substantial Worth or Great Worth

Blank

76

13

Feeling of Happiness Toward Self Very to Slightly Unhappy Very to Slightly Happy Blank 
